\title{
A Deterministic Approach for Approximating the Diurnal Cycle of Precipitation for Use in Large-Scale Hydrological Modeling $\mathscr{O}$
}

\author{
THEODORE J. BOHN \\ Julie Ann Wrigley Global Institute of Sustainability, and School of Earth and Space Exploration, \\ Arizona State University, Tempe, Arizona \\ KRISTEN M. WHITNEY \\ School of Earth and Space Exploration, Arizona State University, Tempe, Arizona \\ GIUSEPPE MASCARO \\ School of Sustainable Engineering and the Built Environment, Arizona State University, Tempe, Arizona \\ ENRIQUE R. VIVONI \\ School of Earth and Space Exploration, and School of Sustainable Engineering and the \\ Built Environment, Arizona State University, Tempe, Arizona
}

(Manuscript received 19 September 2018, in final form 4 January 2019)

\begin{abstract}
Accurate characterization of precipitation $P$ at subdaily temporal resolution is important for a wide range of hydrological applications, yet large-scale gridded observational datasets primarily contain daily total $P$. Unfortunately, a widely used deterministic approach that disaggregates $P$ uniformly over the day grossly mischaracterizes the diurnal cycle of $P$, leading to potential biases in simulated runoff $Q$. Here we present Precipitation Isosceles Triangle (PITRI), a two-parameter deterministic approach in which the hourly hyetograph is modeled with an isosceles triangle with prescribed duration and time of peak intensity. Monthly duration and peak time were derived from meteorological observations at U.S. Climate Reference Network (USCRN) stations and extended across the United States, Mexico, and southern Canada at 6-km resolution via linear regression against historical climate statistics. Across the USCRN network (years 2000-13), simulations using the Variable Infiltration Capacity (VIC) model, driven by $P$ disaggregated via PITRI, yielded nearly unbiased estimates of annual $Q$ relative to simulations driven by observed $P$. In contrast, simulations using the uniform method had a $Q$ bias of $-11 \%$, through overestimating canopy evaporation and underestimating throughfall. One limitation of the PITRI approach is a potential bias in snow accumulation when a high proportion of $P$ falls on days with a mix of temperatures above and below freezing, for which the partitioning of $P$ into rain and snow is sensitive to event timing within the diurnal cycle. Nevertheless, the good overall performance of PITRI suggests that a deterministic approach may be sufficiently accurate for largescale hydrologic applications.
\end{abstract}

Supplemental information related to this paper is available at the Journals Online website: https://doi.org/10.1175/ JHM-D-18-0203.s1.

Corresponding author: Theodore J. Bohn, theodore.bohn@ asu.edu

\section{Introduction}

Accurate characterization of precipitation $P$ at subdaily (e.g., hourly) temporal resolution is important for a wide range of hydrological applications. At small spatiotemporal scales, relations between the intensity, duration, and intermittency of rainfall events and peak rates of runoff $Q$ play a key role in predicting floods and landslides, with important consequences for engineering design (Huff 1967; Arnaud and Lavabre 1999, 2002; Bonnin et al. 2007; Guzzetti et al. 2008; Prein et al. 2017). 
Subdaily $P$ records are also important for modeling the processes controlling runoff generation, due to the strong nonlinear dependence of $Q$ on the differences between $P$ intensity and other fluxes such as evapotranspiration (ET) and soil infiltration (Todini 1988). Indeed, rainfallrunoff modeling studies suggest that, for the same daily total $P$, hyetographs with uniform intensity can yield errors in daily $Q$ of up to $30 \%$, relative to temporally varying hyetographs (Lambourne and Stephenson 1987; Ball 1994). Furthermore, when air temperature is near $0^{\circ} \mathrm{C}$, the timing of $P$ in the diurnal temperature cycle can determine whether $P$ falls as rain or snow (Marks et al. 2013). Thus, even if daily total $P$ is accurate, inaccuracies in subdaily $P$ may yield errors in $Q$ at the time scales (daily and longer) that are commonly of interest to large-scale hydrologic modeling studies.

Unfortunately, observations of $P$ at subdaily resolution (Diamond et al. 2013; Baldocchi et al. 2001) are too sparse and/or too short to be used directly in regional modeling studies. Radar- and satellite-based observations provide regional coverage but have short record lengths and are generally less accurate than gauges (Simpson et al. 1988; Klazura and Imy 1993; Sorooshian et al. 2000; Grassotti et al. 2003; Joyce et al. 2004; Wüest et al. 2010). As a result, the use of subdaily $P$ observations in hydrologic simulations has been limited to physics-based models applied at high resolution and over relatively short time periods at field, hillslope, and small catchment scales (Paniconi and Putti 2015; Schreiner-McGraw and Vivoni 2018; Fatichi et al. 2016).

Large-scale hydrologic modeling studies have instead relied on gridded datasets derived from interpolation of daily $P$ observations, which are more densely distributed and have longer records, enabling spatial resolutions as fine as $1 / 16^{\circ}(\sim 6 \mathrm{~km})$ and time spans from 1950 to present (Maurer et al. 2002; Adler et al. 2003; Adam et al. 2006; Sheffield et al. 2006; Livneh et al. 2013, 2015, hereafter L2015). However, to bridge the gap from daily to hourly resolution, the vast majority of studies using these datasets assumed a uniform $P$ intensity within each rainy day. This yields an unrealistic diurnal cycle of $P$, particularly in summer convective regimes, where the daily total $P$ may be concentrated into a single pulse or just a few events of brief duration (Dai 2001). Despite the aforementioned sensitivity of the hydrologic cycle to subdaily $P$ intensities, the possible biases arising from the uniform assumption have not been investigated at large scales.

Most temporal disaggregation methods are stochastic approaches that treat various aspects of $P$ (e.g., number of events per day, duration, hourly intensities, time of onset, or time of peak) as random variables. Commonly used models are generalizations and improvements of the Neyman-Scott rectangular pulse model, which uses parametric distributions to simulate the occurrence and intensity of single storms within a day (RodriguezIturbe et al. 1984; Arnold and Williams 1989; Katz and Parlange 1995; Connolly et al. 1998; Grimaldi and Serinaldi 2006; Mascaro 2017). Alternative approaches simulate the subdaily temporal variability of $P$ by reproducing the scale invariance and multifractal properties and/or the correlations structure of highresolution $P$ records (Olsson 1998; Deidda et al. 1999; Venugopal et al. 1999; Mascaro et al. 2014).

The use of stochastic approaches to generate subdaily $P$ forcings for large-scale hydrologic simulations is complicated by several issues. First, due to their stochastic nature, these disaggregation models require the generation of multiple random realizations of the subdaily $P$ distribution to characterize its sampling variability. This would imply the adoption of a probabilistic approach for the hydrologic simulations based on an ensemble of runs that may not be computationally feasible. Second, these models are often based on a large number of parameters and simulate several characteristics of $P$ that may be less important for some largescale modeling applications (Maraun et al. 2010). Third, extending these local models to regional scales can involve fitting spatial distributions (Perica and FoufoulaGeorgiou 1996; Mascaro 2017), further increasing the number of parameters and accompanying parameter uncertainty, although some methods do not require more parameters (Domínguez-Mora et al. 2014; Müller and Haberlandt 2015).

In this study, we describe a deterministic approach that is more feasible than stochastic methods to disaggregate daily $P$ products to overcome the potential biases in $Q$ at daily and longer time scales introduced by a uniform $P$ intensity. We considered that 1 ) at minimum, the number of wet and dry hours within the day and the mean within-event intensity should be preserved (Todini 1988); 2) mean timing of the event onset may be important to rain-snow partitioning (Marks et al. 2013); and 3) further details of hyetograph shape (e.g., variability in event timing, distribution of hourly intensities, or timing of the peak relative to onset) play less of a role in $Q$ biases at daily or longer time scales (Stephenson 1984; Lambourne and Stephenson 1987; El-Jabi and Sarraf 1991). The disaggregation algorithm, called Precipitation Isosceles Triangle (PITRI), approximates the daily hyetograph with an isosceles triangle, whose duration and time of peak intensity are held fixed at their average values from a historical reference period. These parameters are each given 12 climatological mean monthly values. Since daily total $P$ is constrained to observed values, preserving the mean observed event duration also preserves the mean 


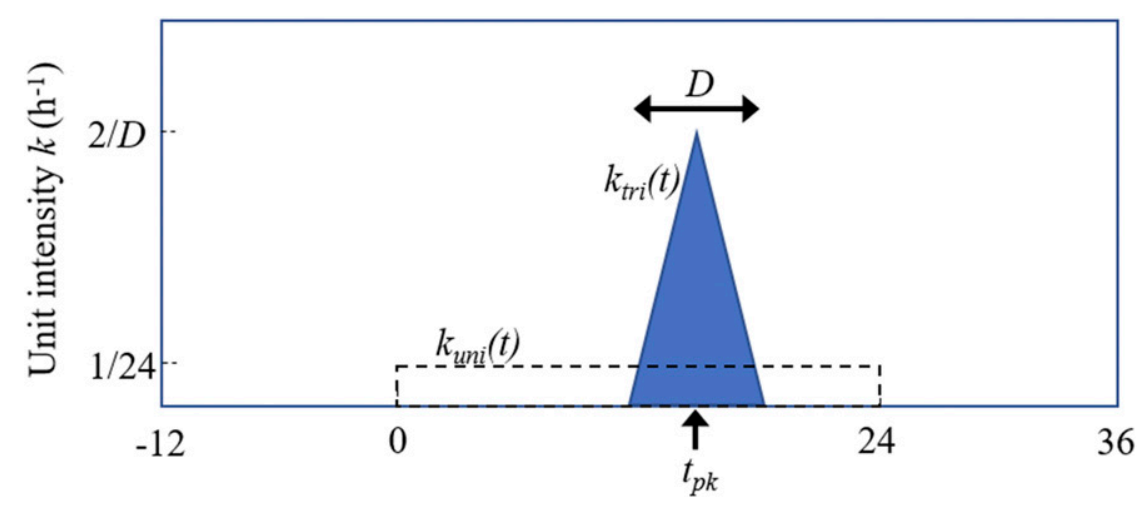

Time $t(\mathrm{~h})$

FIG. 1. The $P$ disaggregation kernels (unit hyetographs) for the uniform (uni) and PITRI (tri) methods.

within-event intensity. Values of event duration are linked to monthly climate statistics in order to allow for adjustments if nonstationarity conditions are identified.

Here we ask the following science questions:

1) What are the impacts of uniform $P$ disaggregation on large-scale hydrological simulations, particularly in terms of bias at daily and longer time scales?

2) Does the PITRI scheme yield improvements in accuracy over the uniform approach, and under which circumstances?

3) Under which circumstances do the lack of temporal variability or small number of parameters of PITRI adversely impact hydrologic simulations?

To answer these questions, we first evaluate the performance of both the PITRI and uniform approaches (denoted by subscripts "tri" and "uni" hereafter) using hourly meteorological observations from the U.S. Climate Reference Network (USCRN; Diamond et al. 2013). Next, we investigate the impact of the disaggregation approaches on the resulting hydrologic fluxes yielded by the Variable Infiltration Capacity (VIC) model (Liang et al. 1994), both at USCRN stations and for gridded simulations over the continental United States, Mexico, and southern Canada.

\section{Methods}

\section{a. Algorithm}

PITRI consists of a two-parameter (per month) equation to disaggregate daily $P$ into a single event per day, describing the event duration, time of occurrence, and distribution of within-event intensities. Each $P$ event is approximated with an isosceles triangle, with a base equal to the event duration and apex located at the event midpoint, with a peak intensity such that the area of the triangle equals the daily total $P$ :

$$
I(d, t)=P_{\text {daily }}(d) k_{\text {tri }}(t),
$$

where $I(d, t)\left(\mathrm{mm} \mathrm{h}^{-1}\right)$ is the instantaneous intensity at time $t$ within day $d, P_{\text {daily }}(d)(\mathrm{mm})$ is the daily total $P$ on day $d$, and $k_{\mathrm{tri}}(t)\left(\mathrm{h}^{-1}\right)$ is the kernel function (unit hyetograph) of the isosceles triangle (Fig. 1):

$$
k_{\mathrm{tri}}(t)=\left\{\begin{array}{c}
\frac{2}{D}+\frac{4}{D^{2}}\left(t-t_{\mathrm{pk}}\right), \quad t_{\mathrm{pk}}-0.5 D<t<t_{\mathrm{pk}}, \\
\frac{2}{D}-\frac{4}{D^{2}}\left(t-t_{\mathrm{pk}}\right), \quad t_{\mathrm{pk}}<t<t_{\mathrm{pk}}+0.5 D, \\
0, \text { all other } t,
\end{array}\right.
$$

where $t_{\mathrm{pk}}$ is the time of day of peak intensity (h) and $D$ is the event duration (h), which is allowed to range from $0.5 d t$ (where $d t$ is the time step length) to $24 \mathrm{~h}$. In Eq. (2), all variables are allowed to take on fractional values; the hyetograph is subsequently aggregated to total $P$ per time step. The corresponding unit hyetograph $k_{\text {uni }}$ of the uniform disaggregation approach is shown for comparison in Fig. 1.

For events that have $t_{\mathrm{pk}}$ within $0.5 \mathrm{D}$ of a day boundary, part of the triangle will fall on a different day. In such cases, up to $50 \%$ of the daily total $P$ may be shifted into a neighboring day. However, this time shift of a half-day of $P$ has only minor impact on the hydrologic budget at seasonal and annual scales, particularly if no $P$ occurs on the first and last days of the interval in question.

\section{b. Study domain}

The study domain spans the region bounded by $14.5^{\circ}$ and $53^{\circ} \mathrm{N}$ latitude and $125^{\circ}$ and $67^{\circ} \mathrm{W}$ longitude (Fig. 2). 


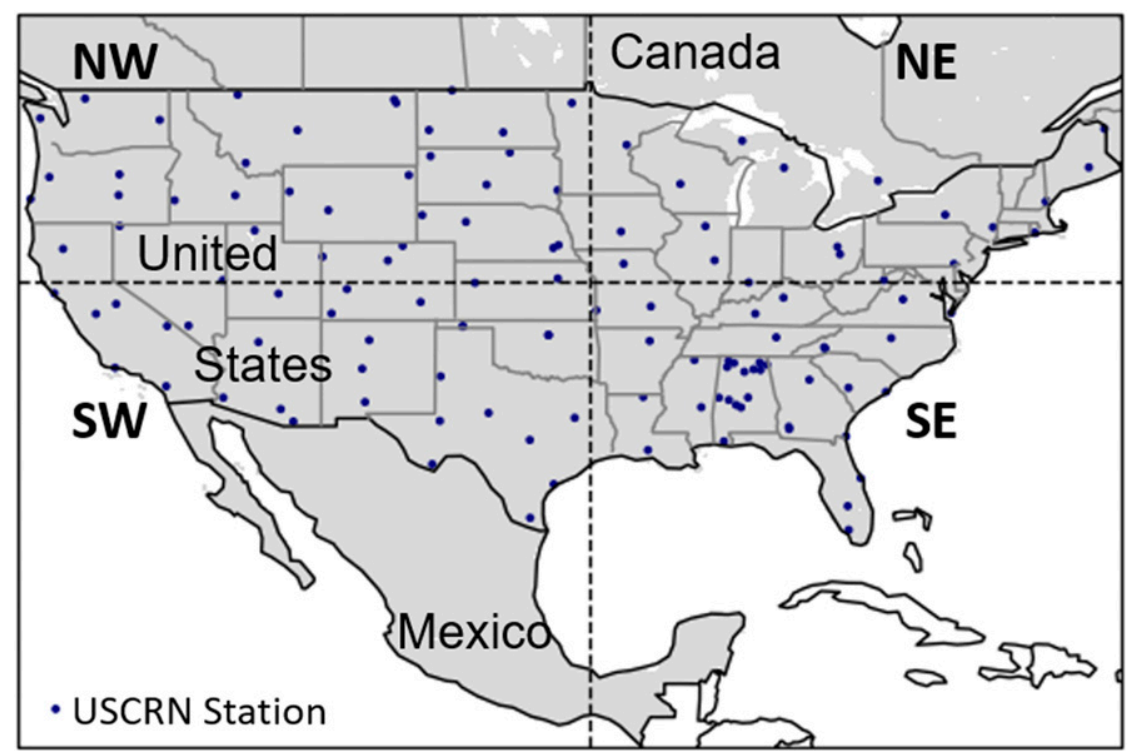

FIG. 2. Study domain (gray region), encompassing the CONUS, Mexico, and southern Canada. Regional quadrants (SW, SE, NW, and NE) are denoted in bold. USCRN stations are denoted with blue dots.

This domain (also used in L2015) is an extension of the contiguous United States (CONUS) domain, over which several gridded meteorology and hydrology datasets (Maurer et al. 2002; Xia et al. 2012; Livneh et al. 2013) have been constructed, to include Mexico; hence, we will refer to the domain as CONUS_MX. To assess geographic variations, we divided the domain into four quadrants (SW, SE, NW, NE) along $39^{\circ} \mathrm{N}$ latitude and $95^{\circ} \mathrm{W}$ longitude.

\section{c. Observational datasets}

Development and evaluation of the algorithm used site-specific hourly observations of $P$ and air temperature $T$ from the USCRN (Diamond et al. 2013). Data were obtained from the start of each station record through 2013 to coincide with the end date of the gridded meteorology products. To ensure reasonably long record lengths and uniform spatial distribution, only the 128 stations whose records began prior to 2008 were used (Fig. 2). Two gridded datasets were obtained and processed to generate continuous fields of disaggregation parameter values across the CONUS_MX domain. First, phase 2 of the North American Land Data Assimilation System (NLDAS-2; Xia et al. 2012) uses an atmospheric model, informed by daily meteorological station observations, to provide continuous fields of hourly meteorological variables at $1 / 8^{\circ}$ spatial resolution over CONUS (from 1979 to present). Second, the gridded daily meteorology product of L2015 interpolates meteorological station data to provide continuous fields of daily $P$, daily minimum and maximum $T\left(T_{\min }\right.$ and $\left.T_{\max }\right)$ and daily average wind speed, at $1 / 16^{\circ}$ spatial resolution over the CONUS_MX domain (1950-2013).

\section{d. Parameter values}

Parameter values were determined in two stages. First, site-specific values were estimated at USCRN stations, and relations between parameter values and climate data were found (described below). Those relations were then applied to gridded meteorological datasets to estimate parameter values over the CONUS_MX domain. Climatological monthly average values of $t_{\mathrm{pk}}$ at USCRN stations were determined as follows: first, hourly $P$ data were grouped by month of year. Next, for each of the 12 months, the mean frequency $F(t)$ of rainfall occurrence in each hour $h$ was calculated (Fig. 3a). Following Mascaro (2017), harmonic analysis was applied to $F(t)$ :

$$
F(t)=F_{0}+F_{1} \cos \left(\omega t-\phi_{1}\right)+\text { "residual", }
$$

where the coefficients $F_{0}$ and $F_{1}$ are the amplitude of the zeroth and first harmonic components, respectively, which are related to the mean and diurnal cycles; $\omega$ is the angular frequency, equal to $2 \pi / 24$, where 24 is the number of hours in a day; and $\phi_{1}$ is the phase angle. Parameters $F_{0}, F_{1}$, and $\phi_{1}$ were estimated via the least squares method and used to compute the time of day of peak $t_{\mathrm{pk}}$ and the amplitude of the cycle. In general, the 

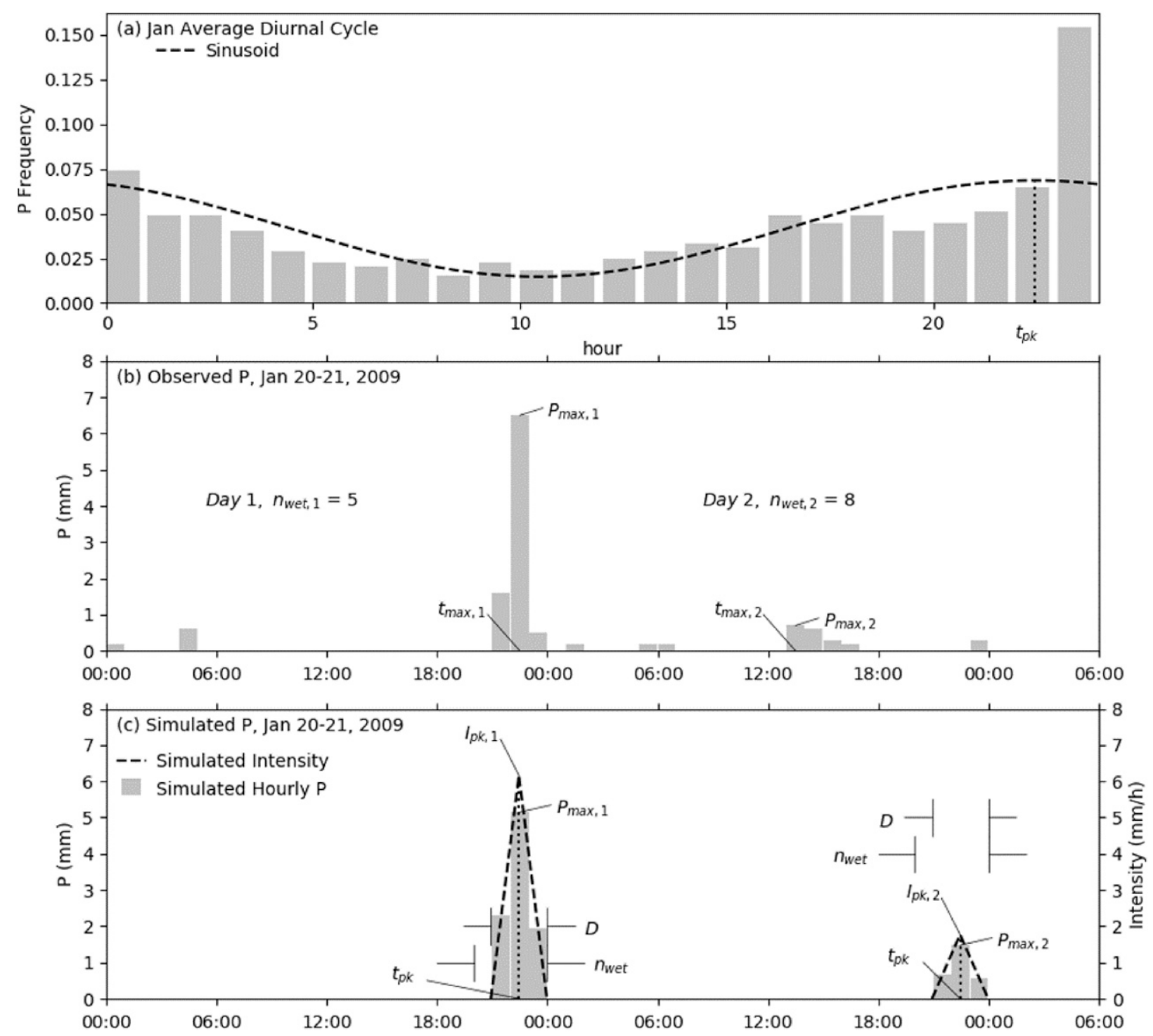

FIG. 3. Example of computation procedure at USCRN station CA_Santa_Barbara_11_W during January 2009. (a) Average diurnal cycle of hourly $P$ for January, with best-fitting sinusoid and corresponding estimate of monthly $t_{\mathrm{pk}}$. (b) Observed hourly $P$ for the period 20-21 Jan, with $n_{\text {wet }}, P_{\max }$, and $t_{\max }$ corresponding to $P_{\max }$ for each day denoted. (c) Simulated instantaneous intensities and hourly $P$ for the same period, with monthly average $t_{\mathrm{pk}}$ and $D$, and daily values of $n_{\mathrm{wet}}, P_{\mathrm{max}}$, and $I_{\mathrm{pk}}$ denoted.

larger the amplitude, the more significant the presence of a strong diurnal cycle. Values of $t_{\mathrm{pk}}$ were expressed in local (solar) time.

To compute spatial means of $t_{\mathrm{pk}}$, we accounted for the periodicity of time of day by computing the angular mean:

$$
\overline{t_{\mathrm{pk}}}=(12 / \pi) \arctan \left[\overline{\sin \left(\pi t_{\mathrm{pk}} / 12\right)} / \overline{\cos \left(\pi t_{\mathrm{pk}} / 12\right)}\right]
$$

To account for periodicity when computing temporal and spatial standard deviations of $t_{\mathrm{pk}}$, we adjusted deviations that fell outside of the interval $[-12 \mathrm{~h}, 12 \mathrm{~h}]$ by adding or subtracting $24 \mathrm{~h}$ before computing the rootmean-square deviation.

Values of $D$ at USCRN stations were derived from the number of "wet" (containing precipitation) hours per wet day $\left(n_{\text {wet }}\right)$ in the record (Fig. 3b). However, because $n_{\text {wet }}$ is a biased estimator of event duration (beginning and ending times occurring at any point within an hour result in the entire hour being designated as wet), a bias correction was employed as follows:

$$
D(d)= \begin{cases}n_{\text {wet }}(d)-0.5, & n_{\text {wet }}(d)=1, \\ n_{\text {wet }}(d)-1, & n_{\text {wet }}(d) \geq 2,\end{cases}
$$


TABLE 1. Major features of the VIC model relevant to this study.

\begin{tabular}{|c|c|c|}
\hline Model component & Feature & Reference \\
\hline \multirow[t]{4}{*}{ Soil column } & $\begin{array}{l}\text { Subgrid variability in runoff generation } \\
\text { (VIC curve) }\end{array}$ & Liang et al. (1994) \\
\hline & Vertical transport between soil layers & $\begin{array}{l}\text { Brooks and Corey (1964); Liang } \\
\text { et al. (1994) }\end{array}$ \\
\hline & Nonlinear base flow & $\begin{array}{l}\text { Franchini and Pacciani (1991); } \\
\text { Liang et al. (1994) }\end{array}$ \\
\hline & Three-soil-layer formulation & Liang et al. (1994) \\
\hline \multirow[t]{4}{*}{ Vegetation } & $\begin{array}{l}\text { Canopy evaporation } E_{\text {can }} \text { and } \\
\text { transpiration } T_{v} \text { via Penman-Monteith } \\
\text { equation }\end{array}$ & Monteith (1965): Liang et al. (1994) \\
\hline & Stomatal resistance & Wigmosta et al. (1994) \\
\hline & Soil evaporation $E_{\text {soil }}$ & $\begin{array}{l}\text { Franchini and Pacciani (1991); } \\
\quad \text { Liang et al. (1994) }\end{array}$ \\
\hline & $\begin{array}{l}\text { Clumped canopy that allows for } E_{\text {soil }} \text { in } \\
\text { canopy gaps }\end{array}$ & Bohn and Vivoni (2016) \\
\hline Snow & Two-layer snowpack & Andreadis et al. (2009) \\
\hline
\end{tabular}

where $d$ is the index of a given wet day, $n_{\text {wet }}(d)$ is the number of wet hours on day $d$, and $D(d)$ is the event duration on day $d$. Climatological monthly values of $D$ at each station were computed as the means of $D(d)$ over wet days. The resulting simulated hourly $P$ may differ from observed hourly $P$ due to large daily variability in observed timing, duration, and peak intensity (Fig. 3c). It should be noted that the discretization of intensities into hourly $P$ values reintroduces the aforementioned bias in $n_{\text {wet }}$ relative to event duration, such that simulated and observed $n_{\text {wet }}$ values will have similar climatological means.

Gridded meteorological datasets were used to provide parameter values over all points in CONUS_MX. Over the CONUS domain, values of $t_{\mathrm{pk}}$ were determined using the NLDAS-2 dataset over the period 1981-2014, subsampled to $0.0625^{\circ}(\sim 6 \mathrm{~km})$ resolution, using the same procedure as for USCRN station records. For points in Mexico south of $25^{\circ} \mathrm{N}$ latitude, values of $t_{\mathrm{pk}}$ were estimated as the average of their values within the rectangle bounded by $25^{\circ}$ and $27^{\circ} \mathrm{N}$ latitude and $115^{\circ}$ and $95^{\circ} \mathrm{W}$ longitude.

Values of event duration $D$ were determined by finding a relation via multiple linear regression between the climatological mean monthly values of $D$ at the USCRN stations and climate statistics of the L2015 dataset in the pixels containing the stations over 1981-2013, and applying this relation to all pixels in the CONUS_MX domain. The relationship had the form

$$
\ln [D(m)]=a+b \ln \left[\overline{P_{\text {mon }}(m)}\right]+c \overline{\operatorname{svp}\left(T_{\text {max }}\right)}(m),
$$

where $m$ is the month (from 1 to 12 ); $a, b$, and $c$ are regression coefficients; $\overline{P_{\text {mon }}(m)}$ is the mean monthly total precipitation $\left(\mathrm{mm}\right.$ month $\left.{ }^{-1}\right)$; and $\overline{\operatorname{svp}\left(T_{\max }\right)}(m)$ is the monthly mean of the saturation vapor pressure $(\mathrm{hPa}$ ) corresponding to daily maximum air temperature $\left({ }^{\circ} \mathrm{C}\right)$ given by the August-Roche-Magnus equation (Alduchov and Eskridge 1996):

$$
\begin{aligned}
\operatorname{svp}\left[T_{\max }(d)\right]= & 6.1094 \exp \left\{17.625 T_{\max }(d) /\left[T_{\max }(d)\right.\right. \\
& +243.04]\} .
\end{aligned}
$$

\section{e. Hydrologic model}

To assess the hydrologic impacts of each $P$ disaggregation method, we employed the VIC model version 5.1 (Hamman et al. 2018). VIC simulates energy and moisture fluxes and storages for the land surface on a regular grid. Within a grid cell, the surface is modeled as a mosaic of land cover tiles, each containing a homogeneous vegetation class atop a three-layer soil column. Relevant VIC features and corresponding references are listed in Table 1. Before incoming $P$ reaches the soil, a portion is intercepted by the vegetation canopy. For liquid precipitation, the available interception storage must be filled completely before any water may reach the soil. Interception storage capacity for rainfall is directly proportional to leaf area index (LAI). Evaporation of canopy water $E_{\text {can }}$ is modeled as potential ET scaled by the ratio of current canopy interception storage to maximum capacity. Evaporation $E_{\text {can }}$ may occur in any time step, even if $P>0$. Canopy throughfall is divided into surface runoff and infiltration according to the fraction of the surface that is saturated $A_{\text {sat }}$, which is positively correlated with soil moisture. Transpiration $T_{v}$ is modeled via the Penman-Monteith equation (Monteith 1965) and draws moisture from 
soil layers in accordance with plant-specific root depth distributions. Transpiration $T_{v}$ is set to zero while the canopy is wet. Soil evaporation $E_{\text {soil }}$ acts on the top layer where soil is exposed. Total runoff $Q$ is the sum of surface runoff and base flow (drainage from the bottom soil layer).

All soil and vegetation parameters were taken from L2015, both for gridded simulations over CONUS_MX and for simulations at USCRN stations. The L2015 parameters were obtained from earlier studies over CONUS (Maurer et al. 2002; Livneh et al. 2013) and Mexico (Zhu and Lettenmaier 2007). In these studies, observable soil properties (e.g., bulk and particle densities, saturated hydraulic conductivity, field capacity) were obtained from the Food and Agricultural Organization Digital Soil Map of the World (FAO/UNESCO 1998); vegetation coverage was taken from the University of Maryland (UMD) Land Cover Classification (Hansen et al. 2000); LAI was derived from Advanced Very High Resolution Radiometer (AVHRR) observations (Myneni et al. 1997); and vegetation canopy and root parameters were taken from literature (Nijssen et al. 2001b). Conceptual soil parameters were calibrated in earlier studies and were not modified here. It should be noted that, although VIC release 4.2 and later allow for $E_{\text {soil }}$ to occur through gaps in the canopy (Bohn and Vivoni 2016), the L2015 parameter does not contain values for canopy fraction $f_{\text {canopy }}$, so that $f_{\text {canopy }}$ defaults to 1.0 for all vegetated land cover classes, which restricts $E_{\text {soil }}$ to only the (relatively rare) bare soil class.

\section{f. Simulations}

To evaluate the impacts of $P$ disaggregation on simulated hydrology, two sets of simulations were performed: site simulations at USCRN stations using observed meteorology, and gridded simulations over CONUS_MX using L2015 meteorology. At the USCRN stations, six versions of meteorological inputs were prepared for input to the VIC model. At both 1-hourly (1 h) and 3-hourly (3h) temporal resolution, three versions of meteorological inputs were prepared, differing only in their derivation of $P$ : directly from subdaily observations (obs) or disaggregated from daily total $P$ via the PITRI (tri) or uniform (uni) methods. PITRI disaggregation used the gridded climatological monthly mean values of $t_{\mathrm{pk}}$ and $D$ from Eq. (6), even for the USCRN simulations, so that the performance of the gridded parameters could be assessed. Meteorological inputs for the VIC model were generated by MetSim (Bennett et al. 2018; Bohn et al. 2013) version 2.0.0_alpha (https://github.com/UW-Hydro/MetSim/releases/ tag/2.0.0_alpha), which not only disaggregated $P$ but also estimated subdaily values of $T$, short- and longwave radiation, vapor pressure, air pressure, and wind speed. Our implementation of PITRI did not account for correlations between $P$ and other meteorological variables at the hourly scale. Inputs to MetSim consisted of daily total $P$ and daily $T_{\min }$ and $T_{\max }$ from the USCRN station records, and daily average wind speed from the L2015 dataset from the grid cells containing the stations. Simulations at USCRN stations spanned the period from the station-specific start date to the end of 2013 (due to the use of L2015 wind values).

Two gridded simulations were performed over the CONUS_MX domain at $0.0625^{\circ}(\sim 6 \mathrm{~km})$ resolution. Both of these used the L2015 daily meteorology, disaggregated to a 1-h time step with the uniform and PITRI approaches over the period 1981-2013. A 5-yr model spinup (from saturated initial conditions) over 1976-80 preceded the simulations. The "uni" simulation essentially recreates the VIC outputs from L2015, save for minor differences in the VIC model version (5.1 vs 4.2) and a shorter evaluation period (1981-2013 vs 1950-2013).

\section{Results}

\section{a. Parameter values}

Across the USCRN network, $t_{\mathrm{pk}}$ exhibited large variability in both space and time, with spatial and temporal standard deviations consistently above $5 \mathrm{~h}$ indicating scattering of events across most hours of the day (Table 2). Several factors may contribute in varying degrees to this variability, including a lack of a strong diurnal cycle, the presence of multiple events per day, and potential sampling error in cases where records are only 6 years long. Because spatial means and standard deviations of $t_{\mathrm{pk}}$ did not account for event size, the diurnal cycle of precipitation could still be pronounced and coherent despite the high variability in $t_{\mathrm{pk}}$. In contrast, $D$ exhibited lower spatial (1-2h) and temporal variability $(2-5 \mathrm{~h})$ and a coherent seasonal cycle, ranging from $4-5 \mathrm{~h}$ in winter to $2-3 \mathrm{~h}$ in summer. Across individual events, $D$ had a standard deviation similar in size to its own mean, that is, a temporal coefficient of variation near 1.0.

Observed mean monthly values of $D$ exhibited a strong relation to mean monthly $\operatorname{svp}\left(T_{\max }\right)$ and $P_{\text {mon }}$ from the L2015 dataset, as shown in Figs. 4a and 4b. The optimal values of the coefficients of Eq. (6) were $a=0.8219$ with $95 \%$ bounds of $(0.776,0.868), b=$ $0.2102(0.200,0.220)$, and $c=-0.0191(-0.020,-0.018)$. All coefficients in Eq. (6) were significant with $p$ values 
TABLE 2. Monthly statistics of precipitation parameters $t_{\mathrm{pk}}$ and $D$ for USCRN stations and gridded parameters. Statistics: $\mu_{s}\left(\mu_{t}\right)=$ mean across stations of monthly mean; $\sigma_{s}\left(\mu_{t}\right)=$ standard deviation across stations of monthly mean; $\mu_{s}\left(\sigma_{t}\right)=$ mean across stations of standard deviation of daily values about monthly mean; $\mu_{s}(\mathrm{RMSE})=$ spatial mean of RMSE of time-invariant gridded parameters relative to their daily observed values at USCRN stations.

\begin{tabular}{|c|c|c|c|c|c|c|c|c|c|c|c|c|}
\hline \multirow[b]{3}{*}{ Month } & \multicolumn{6}{|c|}{ USCRN } & \multicolumn{6}{|c|}{ Gridded parameters } \\
\hline & \multicolumn{3}{|c|}{$t_{\mathrm{pk}}(\mathrm{h})$} & \multicolumn{3}{|c|}{$D(\mathrm{~h})$} & \multicolumn{3}{|c|}{$t_{\mathrm{pk}}(\mathrm{h})$} & \multicolumn{3}{|c|}{$D(\mathrm{~h})$} \\
\hline & $\mu_{s}\left(\mu_{t}\right)$ & $\sigma_{s}\left(\mu_{t}\right)$ & $\mu_{s}\left(\sigma_{t}\right)$ & $\mu_{s}\left(\mu_{t}\right)$ & $\sigma_{s}\left(\mu_{t}\right)$ & $\mu_{s}\left(\sigma_{t}\right)$ & $\mu_{s}\left(\mu_{t}\right)$ & $\sigma_{s}\left(\mu_{t}\right)$ & $\mu_{s}(\mathrm{RMSE})$ & $\mu_{s}\left(\mu_{t}\right)$ & $\sigma_{s}\left(\mu_{t}\right)$ & $\mu_{s}(\mathrm{RMSE})$ \\
\hline Jan & 1.60 & 6.53 & 6.19 & 4.23 & 1.63 & 4.07 & 12.09 & 5.31 & 7.21 & 3.98 & 1.02 & 4.24 \\
\hline Feb & 11.64 & 6.71 & 6.21 & 4.07 & 1.41 & 3.94 & 12.50 & 5.41 & 7.16 & 3.84 & 0.92 & 4.08 \\
\hline Mar & 4.60 & 6.51 & 6.19 & 4.00 & 1.49 & 3.83 & 13.55 & 6.61 & 6.97 & 3.70 & 1.03 & 3.98 \\
\hline Apr & 19.54 & 6.77 & 6.18 & 3.72 & 1.24 & 3.67 & 18.26 & 5.69 & 6.99 & 3.42 & 1.01 & 3.79 \\
\hline May & 8.42 & 6.77 & 5.97 & 3.14 & 1.04 & 3.30 & 18.51 & 4.89 & 6.88 & 3.17 & 0.93 & 3.39 \\
\hline Jun & 5.16 & 6.70 & 5.54 & 2.47 & 0.83 & 2.59 & 16.88 & 4.09 & 6.97 & 2.84 & 0.82 & 2.69 \\
\hline Jul & 8.02 & 6.41 & 5.40 & 2.14 & 1.23 & 2.11 & 16.73 & 4.04 & 6.95 & 2.54 & 0.70 & 2.23 \\
\hline Aug & 3.55 & 6.60 & 5.55 & 2.38 & 1.33 & 2.48 & 16.82 & 4.40 & 6.99 & 2.60 & 0.72 & 2.58 \\
\hline Sep & 0.61 & 6.52 & 5.92 & 3.26 & 1.42 & 3.42 & 17.39 & 6.07 & 6.94 & 3.00 & 0.77 & 3.53 \\
\hline Oct & 0.25 & 6.63 & 6.15 & 3.86 & 1.29 & 3.91 & 19.64 & 6.55 & 6.94 & 3.54 & 0.83 & 4.07 \\
\hline Nov & 13.52 & 6.64 & 6.20 & 4.20 & 1.62 & 4.06 & 10.87 & 6.29 & 7.01 & 3.76 & 0.98 & 4.22 \\
\hline Dec & 23.49 & 6.58 & 6.22 & 4.43 & 1.57 & 4.21 & 10.36 & 4.81 & 7.19 & 4.10 & 1.06 & 4.35 \\
\hline
\end{tabular}

$<0.001$. This relation accounted for $74 \%$ of the variance in $D$ across USCRN stations and months. However, some underestimation of $D$ by $1-6 \mathrm{~h}$ was evident in months that were simultaneously cold [svp $\left(T_{\max }\right)<20 \mathrm{hPa}$, or $\left.T_{\max }<17^{\circ} \mathrm{C}\right]$ and wet $\left(P_{\text {mon }}>\right.$ $200 \mathrm{~mm}$ ). These conditions primarily were found in the mountains along the northern west coast of the domain (Fig. 4c).

Maps of gridded $t_{\mathrm{pk}}$ and $D$ for the months of February and August (representing winter and summer, respectively) are shown in Fig. 5. Other months were essentially transitional between these two extremes. The values of $t_{\mathrm{pk}}$ derived from NLDAS exhibited more spatial and temporal coherence than those from USCRN, with spatial means cycling smoothly between 12 to $20 \mathrm{~h}$, and spatial standard deviations ranging between 4.0 and $6.6 \mathrm{~h}$ (Table 2). In winter, events were generally of longer duration and often peaked during daylight hours, reflecting the predominance of large synoptic systems. In summer, events were generally of shorter duration and tended to peak in late afternoon and early evening, reflecting the predominance of convective systems. A trend in $t_{\mathrm{pk}}$ can be seen extending from the Rocky Mountains to the Great Lakes in August ("2" in Fig. 5b), possibly corresponding to the propagation of storm systems. It should be noted that the discontinuity in $t_{\mathrm{pk}}$ visible at $25^{\circ} \mathrm{N}$ latitude in February ("1" in Fig. 5a), caused by assigning a constant value south of that line, was generally less than $2 \mathrm{~h}$ in magnitude, but appears large in some places due to crossing the day boundary. Spatial mean root-meansquare errors (RMSEs) of the gridded parameters relative to their daily observed values at the USCRN stations ranged between 6.9 and $7.2 \mathrm{~h}$ for $t_{\mathrm{pk}}$ and between 2.2 and $4.4 \mathrm{~h}$ for $D$ (Table 2).

\section{b. Hydrological biases at daily and longer scales}

At USCRN stations, simulations using PITRI substantially outperformed those using the uniform method, relative to using observed $P$, in simulating annual and seasonal water balance terms (Table 3, Fig. 6). PITRI had biases in annual and seasonal $Q$ of less than $1 \%$, at both national (all stations) and regional scales, regardless of time step. These biases were accompanied by small biases in $T_{v}$ and moderate negative biases in $E_{\text {can }}$ (generally smaller than $-10 \%$; however, $E_{\text {can }}$ was generally an order of magnitude smaller than either $Q$ or $T_{v}$ ). In contrast, at the national scale, the uniform method had biases in $Q$ of $-11.4 \%$ and $-6.2 \%$ at $1-\mathrm{h}$ and 3-h time steps, accompanied by large biases $(227 \%$ and $147 \%)$ in $E_{\text {can }}$ and moderate negative biases in $T_{v}$ $(-13 \%$ and $-7 \%)$. Thus, spreading $P$ uniformly throughout the day boosted $E_{\text {can }}$ by giving the canopy more chances to fill, evaporate, and refill, thereby reducing both $Q$ and $T_{v}$. For the uniform method, biases in $Q$ varied regionally, from $-9 \%$ and $-5 \%$ in $\mathrm{NW}$ to $-17 \%$ and $-8 \%$ in SW, at $1-$ and 3 -h time steps, respectively. Biases in $E_{\text {can }}$ were much larger (in both relative and absolute terms) during spring and summer than autumn and winter, indicating an important role for air temperature.

However, the uniform method outperformed PITRI in terms of annual maximum snow water equivalent $\left(\mathrm{SWE}_{\max }\right)$ in the NW and NE regions, where the two methods yielded biases of $-9 \%$ and $+6 \%$ (PITRI) and $0 \%$ and $4 \%$ (uniform), respectively (Fig. 6d, Table 4 ). 

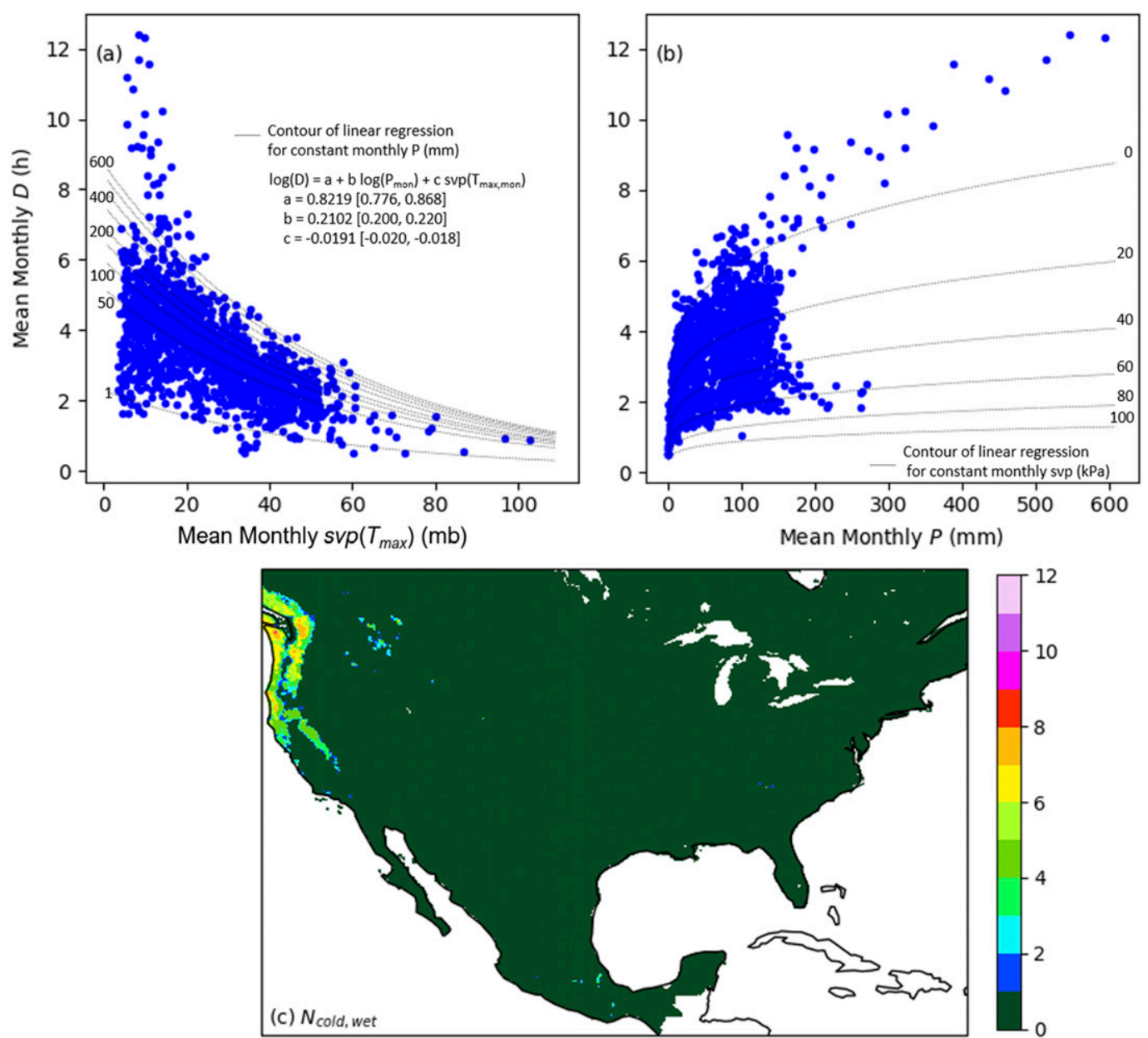

FIG. 4. Relationships between mean monthly duration $D$ computed from USCRN station records vs mean monthly climate statistics from the L2015 dataset over the period 1981-2013. The $x$-axis values are (a) mean monthly svp corresponding to $T_{\max }$, (b) mean monthly $P$, and (c) map of number of months per year for which $\operatorname{svp}\left(T_{\max }\right)<20$ and $P>200 \mathrm{~mm}$. Dashed curves in (a) and (b) illustrate contours of linear regression from Eq. (6).

The reason for the worse performance of PITRI was due to the invariance of event timing on days in which air temperature $T_{\text {air }}$ passed through $0^{\circ} \mathrm{C}$. On these rainsnow transition days, the timing of events relative to the diurnal cycle of $T_{\text {air }}$ impacted the partitioning of $P$ into rain and snow, as illustrated for the Darrington, Washington, station for the month of November in Fig. 7. Here, the scatter in observed $P$ event timing was large enough that the average diurnal cycle of observed $P$ was nearly uniformly distributed, while PITRI held event timing constant in the afternoon (Fig. 7a). But $T_{\text {air }}$ was most likely to be above freezing in the afternoon (Fig. 7b), so that simulations using PITRI yielded less snowfall (Fig. 7c) and lower snow accumulation (Fig. 7d) than simulations using observed $P$ or uniform disaggregation.

\section{c. Hourly and daily statistics of $P$ and $Q$}

Although the PITRI method outperformed the uniform method in terms of long-term bias, performance in terms of other metrics was mixed (Table 5; statistics at regional and seasonal scales listed in Tables S1-S3 in the online supplemental material). For daily total $Q\left(Q_{\text {day }}\right)$, PITRI slightly outperformed the uniform method in general, due to its smaller bias. Over all stations and all months in aggregate, at 1-h time step, PITRI had an average correlation with observations of 0.966 , RMSE of $0.502 \mathrm{~mm} \mathrm{day}^{-1}$, and Nash-Sutcliffe efficiency (NSE) of 0.895 , while the uniform method had correlation, RMSE, and NSE values of $0.950,0.509 \mathrm{~mm} \mathrm{day}^{-1}$, and 0.859 , respectively. PITRI generally outperformed the uniform method at the regional and seasonal scales as well, with the exception of summer and autumn in the 

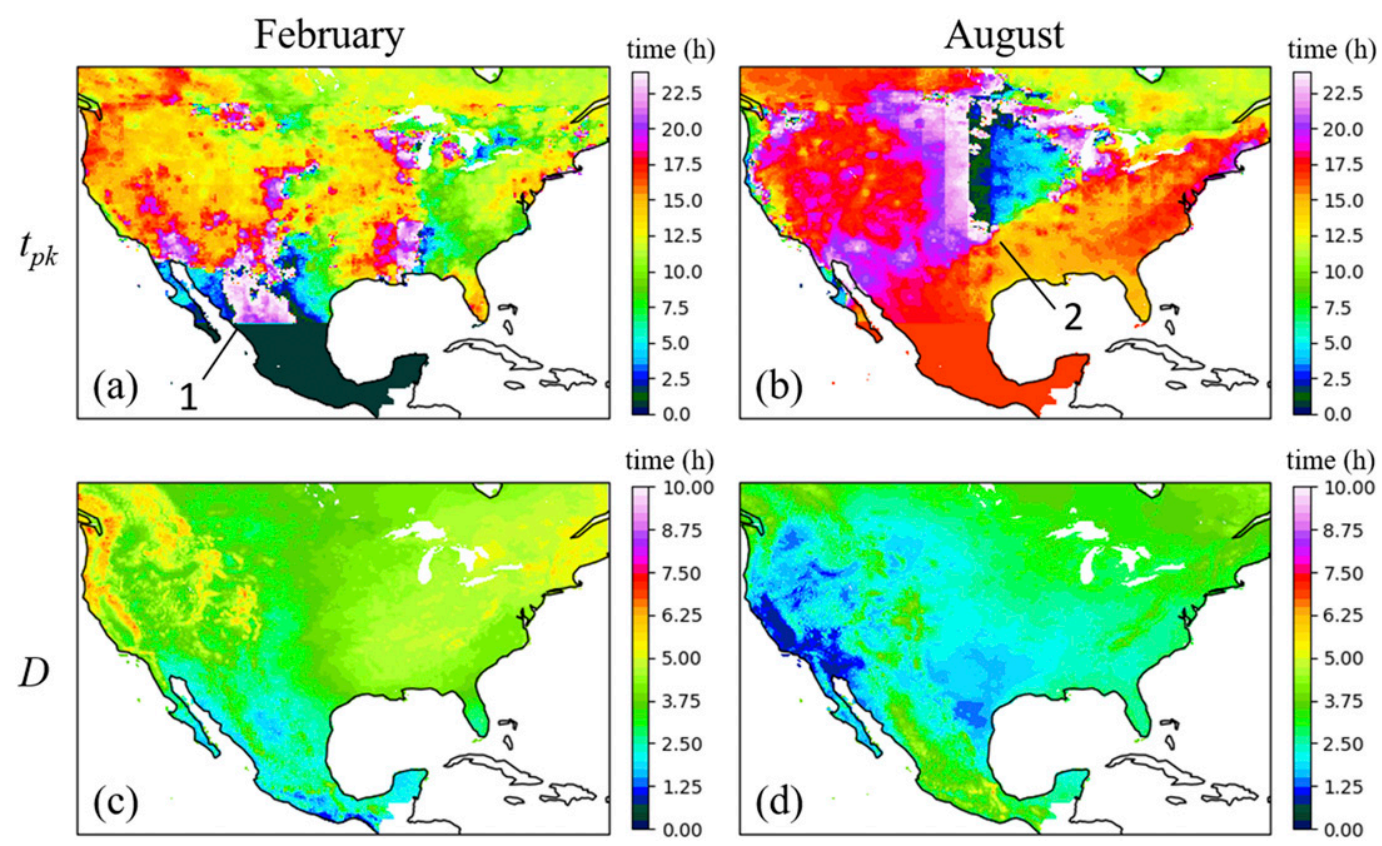

FIG. 5. Maps of $P$ disaggregation parameters in February and August: (a),(b) $t_{\mathrm{pk}}$ and (c),(d) $D$. Values of $t_{\mathrm{pk}}$ are expressed in local (solar) time.

$\mathrm{NE}$ and SE regions, where PITRI had a large amplitude ratio $\left(\sigma_{\text {sim }} / \sigma_{\text {obs }}\right)$ of $1.2-1.3$ (Table S3).

Both methods performed worse in simulating subdaily extremes. For maximum subdaily $P$ of the day $\left(P_{\max }\right)$, across all USCRN stations, PITRI had a bias of $14 \%$, correlation of 0.839 , and RMSE and NSE values of $3.141 \mathrm{~mm} \mathrm{~h}^{-1}$ and 0.400 (Table 5). Yet, the PITRI method still outperformed the uniform method, which had RMSE and NSE values of $5.314 \mathrm{~mm} \mathrm{~h}^{-1}$ and -0.230 , respectively, due to its bias of $-90 \%$. PITRI outperformed the uniform method in most regions and seasons except for autumn and winter in the NW and SW regions, when PITRI had biases of $30 \%-40 \%$ (Table S1). This may be due to the underestimation of $D$ in Eq. (6) for the coldest and wettest months (Fig. 4c). For maximum subdaily $Q$ of the day $\left(Q_{\max }\right)$, the uniform method (RMSE and NSE of $0.457 \mathrm{~mm} \mathrm{~h}^{-1}$ and 0.186 , respectively) outperformed PITRI (RMSE and NSE of $0.523 \mathrm{~mm} \mathrm{~h}^{-1}$ and -0.485 , respectively), due to PITRI having an amplitude ratio of 1.6 and bias of $18 \%$ (Table 5). However, the uniform method also performed poorly, with a bias of $-66 \%$.

\section{d. Conditional biases}

Errors of the methods exhibited strong dependence on the size of the term being simulated, as shown in Fig. 8 for $P_{\max }, Q_{\max }$, and $Q_{\text {day }}$. Similar analyses of errors on a seasonal basis are shown in Figs. S1-S3. In these plots, points were generated by 1) computing monthly average errors of the daily variables of interest from the tri and uni simulations (as a percentage of the variable from the obs simulation) for each month of record at each USCRN station (for $P_{\max }$, averages excluded dry days); 2) dividing the natural logarithm of the obs variable into 500 bins of equal width spanning from $10^{-3}$ to $10^{2} \mathrm{~mm} \mathrm{~h}^{-1}$; and 3) for each bin, computing the average error and average obs value across all station months for which the obs value fell into the bin. These averages across station months became the $y$ and $x$ coordinates of the points. Locally weighted scatterplot smoothing (LOWESS) curves with 100-point window lengths were drawn to aid interpretation. Shading indicates the range between the 10th and 90th percentiles of the distribution of obs values.

For all three variables, errors for the PITRI method tended to be positive and relatively small, while errors for the uniform method were negative and larger. This pattern was most evident for $P_{\max }$ (Figs. 8a,b), for which PITRI yielded mean errors of +15 and $+20 \%$ at 1- and 3-h time steps, and the uniform method had mean errors of $-90 \%$ and $-80 \%$. In contrast to the relatively constant errors of the uniform method, the PITRI method exhibited a "hump," with peak values of $15 \%-25 \%$ for $1 \mathrm{~mm} \mathrm{~h}^{-1}<P_{\text {max,obs }}<10 \mathrm{~mm} \mathrm{~h}^{-1}$. Below this range, errors were under $15 \%$. Above $10 \mathrm{~mm} \mathrm{~h}^{-1}$, errors declined, even becoming negative at the highest values of $P_{\text {max,obs }}$. 
TABLE 3 . Biases in mean annual and seasonal $Q, E_{\mathrm{can}}$, and $T_{v}$ simulated by the VIC model at 128 USCRN stations, when driven by $P$ from PITRI and uniform disaggregation, relative to simulated $Q$ driven by observed $P$, as a function of region, season, and time step.

\begin{tabular}{|c|c|c|c|c|c|c|c|c|c|c|c|c|c|}
\hline \multirow[b]{4}{*}{ Region } & \multirow[b]{4}{*}{ Period } & \multicolumn{12}{|c|}{ Bias (\%) } \\
\hline & & \multicolumn{6}{|c|}{$1 \mathrm{~h}$} & \multicolumn{6}{|c|}{$3 \mathrm{~h}$} \\
\hline & & \multicolumn{3}{|c|}{ PITRI } & \multicolumn{3}{|c|}{ Uniform } & \multicolumn{3}{|c|}{ PITRI } & \multicolumn{3}{|c|}{ Uniform } \\
\hline & & $Q$ & $E_{\text {can }}$ & $T_{v}$ & $Q$ & $E_{\text {can }}$ & $T_{v}$ & $Q$ & $E_{\text {can }}$ & $T_{v}$ & $Q$ & $E_{\text {can }}$ & $T_{v}$ \\
\hline \multirow[t]{5}{*}{ All stations } & Annual & 0.39 & -6.05 & 0.23 & -11.41 & 227.48 & -13.70 & 0.41 & -16.01 & 0.84 & -6.16 & 147.25 & -7.44 \\
\hline & Winter & 0.36 & -3.95 & 0.41 & -8.58 & 189.97 & -10.73 & 0.36 & -12.75 & 0.93 & -4.83 & 113.15 & -5.84 \\
\hline & Spring & -0.14 & -3.46 & 0.54 & -11.12 & 237.99 & -11.78 & 0.07 & -16.78 & 1.08 & -5.59 & 152.87 & -6.26 \\
\hline & Summer & 1.01 & -4.76 & -0.04 & -16.81 & 254.41 & -16.17 & 0.82 & -14.60 & 0.67 & -9.52 & 168.13 & -8.84 \\
\hline & Autumn & 0.60 & -14.73 & -0.08 & -11.87 & 178.22 & -13.39 & 0.58 & -20.26 & 0.46 & -6.31 & 113.42 & -7.63 \\
\hline \multirow[t]{5}{*}{ NW } & Annual & 0.21 & -5.31 & 1.07 & -9.26 & 190.15 & -13.86 & 0.43 & -14.95 & 2.68 & -5.45 & 116.06 & -6.38 \\
\hline & Winter & 0.00 & 9.45 & 2.29 & -5.92 & 98.48 & -13.19 & 0.19 & -5.98 & 5.02 & -3.86 & 57.48 & -9.00 \\
\hline & Spring & -0.46 & -5.33 & 1.43 & -11.65 & 205.00 & -11.80 & 0.03 & -18.72 & 1.84 & -6.43 & 125.00 & -6.30 \\
\hline & Summer & 0.46 & -12.03 & 0.55 & -16.34 & 261.60 & -15.86 & 0.54 & -15.92 & 0.77 & -9.00 & 167.47 & -8.24 \\
\hline & Autumn & 1.27 & -5.37 & 1.77 & -7.30 & 109.27 & -15.47 & 1.26 & -13.55 & 2.83 & -4.63 & 64.50 & -9.84 \\
\hline \multirow[t]{5}{*}{$\mathrm{NE}$} & Annual & 0.36 & -13.11 & 0.82 & -10.55 & 196.28 & -15.01 & 0.41 & -22.13 & 2.77 & -6.12 & 138.81 & -8.22 \\
\hline & Winter & 0.65 & -8.24 & -1.17 & -7.76 & 184.62 & -10.68 & 0.70 & -15.38 & -0.60 & -4.93 & 102.56 & -7.80 \\
\hline & Spring & 0.16 & -8.65 & 0.93 & -8.82 & 207.10 & -13.07 & 0.22 & -20.27 & 1.46 & -4.30 & 141.92 & -7.87 \\
\hline & Summer & 0.95 & -12.20 & 0.75 & -16.09 & 199.04 & -16.64 & 1.17 & -22.06 & 1.54 & -10.14 & 147.01 & -10.63 \\
\hline & Autumn & 0.02 & -28.00 & 1.24 & -12.88 & 165.83 & -16.18 & -0.11 & -29.21 & 1.00 & -7.55 & 110.79 & -9.45 \\
\hline \multirow[t]{5}{*}{ SW } & Annual & 0.41 & -5.06 & 0.47 & -17.26 & 357.43 & -11.30 & 0.51 & -14.99 & 0.59 & -8.13 & 206.70 & -4.84 \\
\hline & Winter & -0.32 & 2.16 & 0.84 & -13.26 & 287.77 & -8.64 & -0.25 & -11.11 & 1.02 & -6.59 & 163.63 & -3.59 \\
\hline & Spring & -0.37 & -3.95 & 0.58 & -17.78 & 375.89 & -8.65 & -0.12 & -12.97 & 0.65 & -8.64 & 216.76 & -3.69 \\
\hline & Summer & 1.16 & -8.29 & 0.30 & -22.35 & 396.23 & -14.80 & 1.04 & -17.64 & 0.43 & -10.42 & 231.14 & -6.34 \\
\hline & Autumn & 2.11 & -4.43 & 0.30 & -18.99 & 293.67 & -11.18 & 2.36 & -14.16 & 0.55 & -8.03 & 169.03 & -4.88 \\
\hline \multirow[t]{5}{*}{$\mathrm{SE}$} & Annual & 0.48 & -2.63 & -0.68 & -11.83 & 241.21 & -14.06 & 0.90 & -13.20 & 1.84 & -5.68 & 161.30 & -6.23 \\
\hline & Winter & 0.53 & -12.28 & -0.17 & -9.39 & 221.53 & -11.16 & 0.39 & -17.63 & 0.11 & -4.91 & 113.15 & -6.00 \\
\hline & Spring & -0.15 & 1.61 & -0.32 & -11.03 & 259.77 & -12.55 & -0.01 & -13.23 & 0.54 & -5.38 & 152.87 & -6.60 \\
\hline & Summer & 1.20 & 5.30 & -1.14 & -16.26 & 257.18 & -16.75 & 0.74 & -7.25 & 0.14 & -9.29 & 168.13 & -9.35 \\
\hline & Autumn & 0.43 & -15.70 & -0.87 & -12.28 & 199.87 & -13.21 & 0.45 & -20.07 & -0.20 & -6.03 & 113.42 & -7.59 \\
\hline
\end{tabular}

For $Q$, the largest errors in both methods were confined to the extreme values. Across the most common values (10th-90th percentiles) of $Q_{\max }$ (Figs. 8c,d), the PITRI method had mean errors of $+15 \%$ and $+10 \%$ at 1- and 3-h time steps, while the uniform method had mean errors of $-25 \%$ and $-15 \%$. For $Q_{\text {day }}$ (Figs. $8 \mathrm{e}, \mathrm{f}$ ), the PITRI method vastly outperformed the uniform method, with errors clustered around $1 \%$ at both 1 - and 3 -h time steps, compared to mean errors of $-20 \%$ and $-10 \%$ for the uniform method.

Factors that help explain the behaviors of the errors of these methods are shown in Fig. 9. Note that the $x$ axis in all panels is $P_{\text {max,obs }}$ (monthly average observed maximum subdaily $P$ of the day) plotted on a logarithmic scale for consistency. Again, points represent averages across all station months for which $P_{\max , o b s}$ fell into a given bin. For $P_{\text {max,obs }}$ at 1 -h time step (Fig. 9a), the "hump" in the errors of the PITRI method may be explained by two competing factors. First, between 1 and $10 \mathrm{~mm} \mathrm{~h}^{-1}, P_{\text {max,obs }}$ was highly correlated with $\overline{\left(D_{\text {mon }}\right)}(m)$ (Fig. $\left.9 b\right)$. Because PITRI used a fixed duration equal to $\overline{\left(D_{\text {mon }}\right)}(m)$, PITRI underestimated the duration (and therefore overestimated the intensity) of events with observed $D>\overline{\left(D_{\text {mon }}\right)}(m)$ that were associated with high values of $P_{\text {max,obs. }}$ Second, above $10 \mathrm{~mm} \mathrm{~h}^{-1}, P_{\text {max }, \text { obs }}$ was highly correlated with the skewness of hourly $P$ during the event (Fig. 9c). Because triangles have skewness of 0 , PITRI tended to underestimate the peak intensities of the high-skewness events associated with these same high values of $P_{\text {max,obs }}$, eventually cancelling out the duration-based errors, and leading to declining errors for PITRI. The uniform method suffered from the same characteristics, namely, fixed $D$ and 0 skewness (and indeed exhibited a small hump above $1 \mathrm{~mm} \mathrm{~h}^{-1}$ ), but because $D$ is always $24 \mathrm{~h}$, the errors were dominated by the gross underestimate of event intensity.

Differences in biases of $P_{\max }$ between the two methods led to large differences in ET components. The positive bias in PITRI for $P_{\text {max,obs }}$ above values of $1 \mathrm{~mm} \mathrm{~h}^{-1}$ yielded greater throughfall and $25 \%$ less $E_{\text {can }}$ than for $P_{\text {obs }}$ (Fig. 9d). The greater throughfall in turn led to greater infiltration and fewer time steps with large values of wet surface area fraction $f_{w}$ in the canopy, both of which led to greater $T_{v}$ (Fig. 9e). 

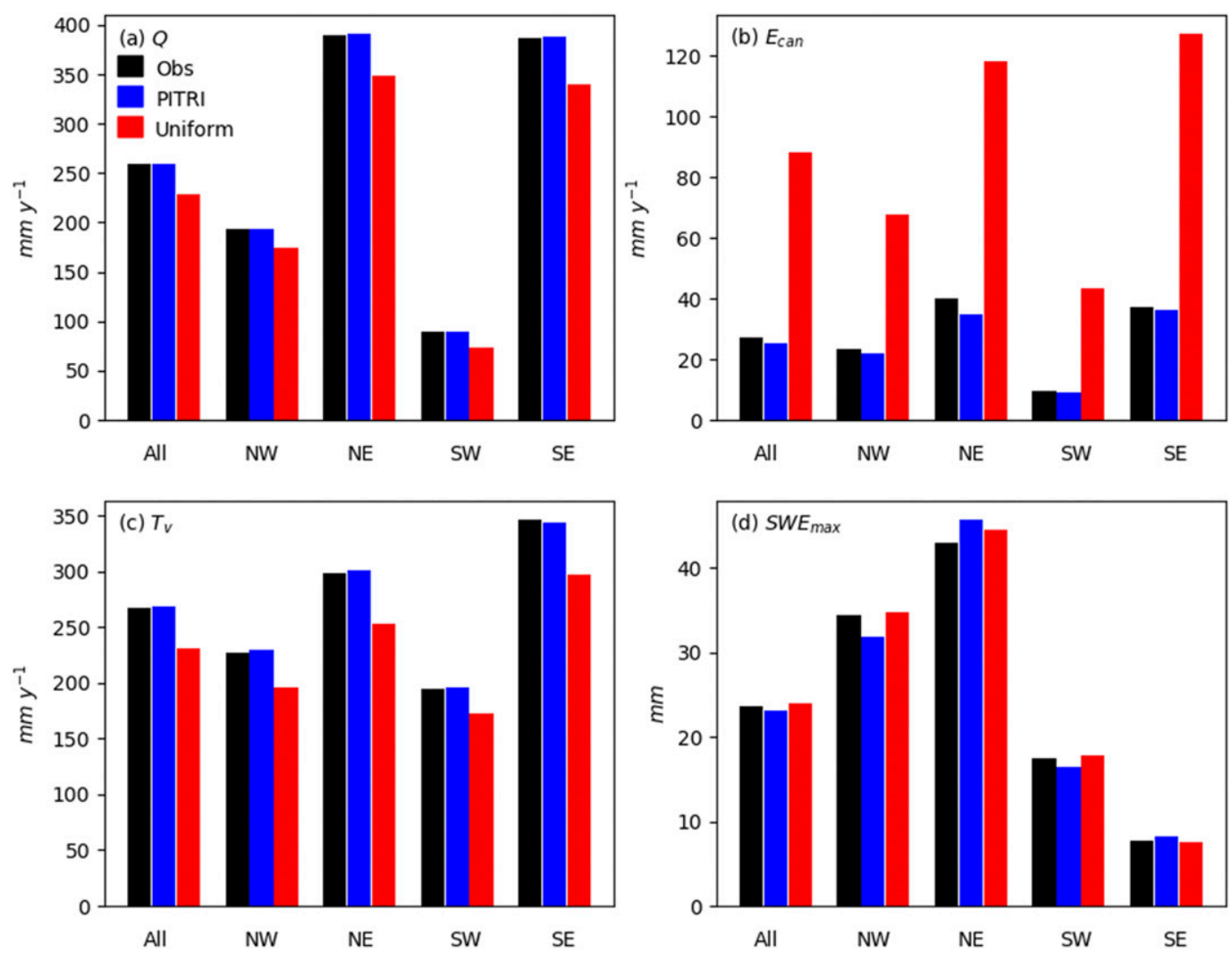

FIG. 6. Mean annual water balance terms from 1-h VIC simulations at USCRN stations, driven by observed $P$ (Obs), PITRI disaggregation, and uniform disaggregation: (a) $Q$, (b) $E_{\text {can }}$, (c) $T_{v}$, and (d) $\mathrm{SWE}_{\max }$. Values are averages over all stations (All) or stations within the four subregions (NW, NE, SW, SE).

This impact, however, was spread over all $P_{\text {max,obs }}$ values due to $T_{v}$ drawing from soil moisture, which was sensitive to the cumulative impact of these biases. In contrast, the smaller intensities and longer durations of the uniform method allowed the canopy interception storage to fill, evaporate, and refill during each rainy day. This led to over 3 times larger $E_{\text {can }}$ than for $P_{\text {obs }}$ (Fig. 9d), and correspondingly smaller throughfall, soil moisture, and $T_{v}$ (Fig. 9e) at all values of $P_{\max }$. The net result of these biases in $E_{\text {can }}$ and $T_{v}$ was that the uniform method underestimated total ET for $P_{\text {max obs }}<0.2 \mathrm{~mm} \mathrm{~h}^{-1}$, but substantially overestimated ET by up to $50 \%$ for larger values of $P_{\max , \text { obs }}$ (Fig. 9f).

Biases in $E_{\text {can }}$ and $T_{v}$ led to corresponding biases in soil moisture and saturated fraction $A_{\text {sat }}$ (Fig. 9g). For the PITRI method, $A_{\text {sat }}$ was essentially unbiased except for the largest values $\left(>10 \mathrm{~mm} \mathrm{~h}^{-1}\right)$ of $P_{\text {max,obs }}$, for which they reached $20 \%$. For the uniform method, $A_{\text {sat }}$ errors exhibited wide scatter at small values of $P_{\text {max,obs }}$, coalesced between $-10 \%$ and $-15 \%$ at medium values of $P_{\text {max,obs, }}$, and became increasingly negative thereafter. Errors in $Q_{\text {day }}$ followed errors in $A_{\text {sat }}$ closely, particularly at large values of $P_{\text {max,obs }}$ (Fig. 9h), which is plausible given that at large values of $P_{\text {max,obs }}$, $A_{\text {sat }}$ controls the fraction of throughfall that becomes surface runoff. For $Q_{\text {max }}$ (Fig. 9i), errors of both methods were small at small values of $P_{\text {max,obs }}$ but increasingly resembled errors in $P_{\max }$ (Fig. 9a) at values of $P_{\text {max obs }}$ large enough to fill the canopy in a single time step.

\section{e. Gridded simulations}

Gridded simulations largely followed the same behaviors observed at USCRN stations. However, certain

TABLE 4. Biases in mean annual SWE $\mathrm{SWax}_{\operatorname{mat}}$ simulat by the VIC model at 1-h time step at 128 USCRN stations, when driven by $P$ from PITRI and uniform disaggregation, relative to mean annual $\mathrm{SWE}_{\max }$ driven by observed $P$, as a function of region.

\begin{tabular}{lrc}
\hline \multirow{2}{*}{ Region } & \multicolumn{2}{c}{ Bias (\%) } \\
\cline { 2 - 3 } & PITRI & Uniform \\
\hline All Stations & -2.24 & 1.54 \\
NW & -8.83 & 0.32 \\
NE & 5.66 & 4.45 \\
SW & -4.44 & 2.97 \\
SE & 1.75 & -4.50 \\
\hline
\end{tabular}



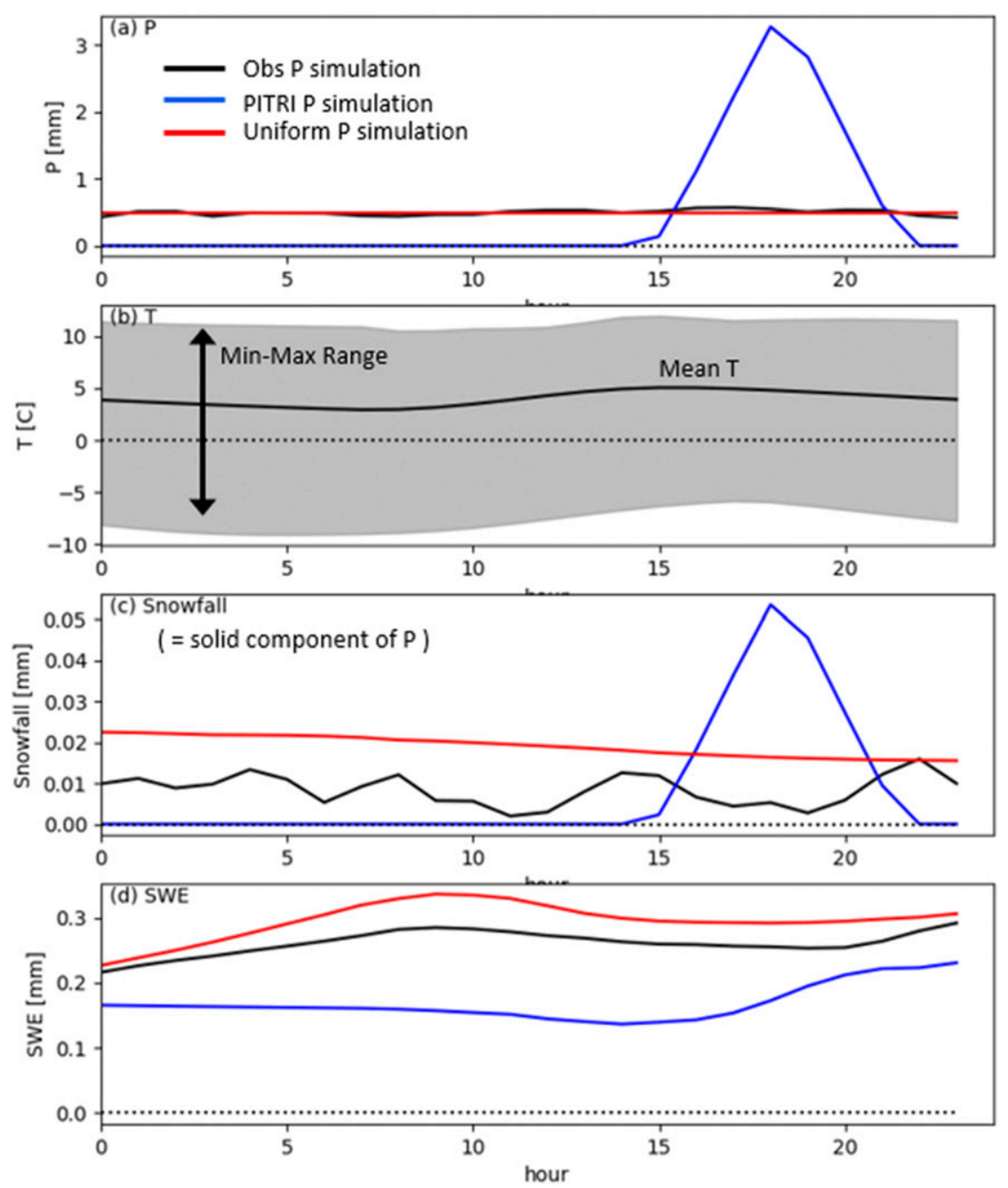

FIG. 7. Average diurnal cycles of simulated hydrologic terms from the Darrington, WA, USCRN station for the month of November, 2003-13, from simulations driven by observed $P$ and $P$ disaggregated by PITRI or uniform methods: (a) $P$, (b) $T_{\text {air }}$, (c) snowfall, and (d) SWE. Shading in (b) indicates the range of all $T_{\text {air }}$ values across all days, for each hour.

spatial patterns became evident (Fig. 10). Mean annual $Q$ for the two methods $\left(Q_{\text {tri }}\right.$ and $\left.Q_{\text {uni }}\right)$ was largest east of $95^{\circ} \mathrm{W}$ longitude, south of $20^{\circ} \mathrm{N}$ latitude, and in the mountains and coasts of the western United States and Canada (Figs. 10a,b). However, although their difference $\Delta Q$ (Fig. 10c) was large and negative in the eastern and southern portions of the domain, it was conspicuously small (and positive in some cases) in the western coasts and mountains (denoted by box 1 ). Differences in $E_{\text {can }}$ and $T_{v}$ followed similar patterns to $\Delta Q$ (Figs. 10d,e), despite both $P$ and LAI being quite large in box 1 (Figs. 10f,g). Normalizing $\Delta Q$ by $Q_{\text {tri }}$ (Fig. 10h) made this pattern clearer: biases in $Q_{\text {uni }}$ (relative to $Q_{\text {tri }}$ ) fell in the range from $-10 \%$ to $-20 \%$ over most of the eastern and southern portions of the domain and reached $-50 \%$ at places in the central United States, but over the western mountains and coasts, $\Delta Q$ became nearly 0 or slightly positive.

The lower sensitivity of this region to the choice of $P$ disaggregation method is explained by two primary factors. First, this region has a Mediterranean climate, in which the majority of annual $P$ falls in "cold" months for which mean $T_{\max }<10^{\circ} \mathrm{C}$ (Fig. 10i). Under these conditions, $E_{\text {can }}$ is relatively small, so that any biases resulting from the uniform approach have little impact. Second, a high proportion of annual $P$ in this region falls on "transition" days (days for which $T_{\min }<$ $0^{\circ} \mathrm{C}$ and $T_{\max }>0^{\circ} \mathrm{C}$; Fig. $10 \mathrm{j}$ ), for which the phase of $P$ (rain or snow) is highly sensitive to the timing of $P$ (as illustrated in Fig. 6). Because typical winter 
TABLE 5. Spatial mean performance statistics of simulations at 1-h time step using the PITRI and uniform disaggregation methods in reproducing maximum hourly $P$ and $Q$ of the day $\left(P_{\max }\right.$ and $\left.Q_{\max }\right)$ and daily total $Q\left(Q_{\text {day }}\right)$ across 128 USCRN stations. Variables: $\mu_{\mathrm{sim}} / \mu_{\mathrm{obs}}=$ ratio of means from simulations using disaggregated (sim) and observed (obs) $P ; \sigma_{\mathrm{sim}} / \sigma_{\mathrm{obs}}=$ ratio of standard deviations from sim and obs $P ; r(\operatorname{sim}$, obs $)=$ correlation coefficient between output of sim and obs simulations.

\begin{tabular}{|c|c|c|c|c|c|c|}
\hline \multirow[b]{2}{*}{ Variable } & \multirow[b]{2}{*}{ Method } & \multicolumn{5}{|c|}{ Metric } \\
\hline & & $\mu_{\mathrm{sim}} / \mu_{\mathrm{obs}}$ & $\sigma_{\mathrm{sim}} / \sigma_{\mathrm{obs}}$ & $r(\operatorname{sim}, \mathrm{obs})$ & RMSE & NSE \\
\hline \multirow{2}{*}{$P_{\max }\left(\mathrm{mm} \mathrm{h}^{-1}\right)$} & PITRI & 1.141 & 1.240 & 0.839 & 3.141 & 0.400 \\
\hline & Uniform & 0.099 & 0.107 & 0.817 & 5.314 & -0.230 \\
\hline \multirow[t]{2}{*}{$Q_{\max }\left(\mathrm{mm} \mathrm{h}^{-1}\right)$} & PITRI & 1.181 & 1.624 & 0.829 & 0.523 & -0.485 \\
\hline & Uniform & 0.337 & 0.255 & 0.679 & 0.457 & 0.186 \\
\hline \multirow[t]{2}{*}{$Q_{\text {day }}\left(\mathrm{mm} \mathrm{day}^{-1}\right)$} & PITRI & 1.006 & 1.080 & 0.966 & 0.502 & 0.895 \\
\hline & Uniform & 0.849 & 0.872 & 0.950 & 0.509 & 0.859 \\
\hline
\end{tabular}

events simulated via PITRI had durations of 5-6 h and peak intensities occurring between 1500 and 1800 local time (Fig. 5), at least $50 \%$ of the $P$ falling on transition days fell during the relatively warm afternoon, when it was more likely to fall as rain, leading to negative biases in annual maximum snow water equivalent $\left(\mathrm{SWE}_{\max }\right)$. In contrast, the uniform disaggregation approach only assigned $25 \%$ of the daily total $P$ to the afternoon, leading to less biased snow accumulation rates than the PITRI method in these areas (Fig. 10k). This larger snowpack generated greater snowmelt and infiltration into the soil in the following spring, more than compensating for the greater values of $E_{\text {can }}$ that occurred during warm season $P$ events (Fig. 11). The underestimation of $D$ by Eq. (6) for the wettest months (Fig. 4c) also undoubtedly played a role in these snow accumulation biases, as longer-duration events would distribute some $P$ in colder times of day. Thus, while simulations using PITRI were essentially unbiased at the annual scale, the invariant timing of $P$ events in winter in the western United States led to small biases at the seasonal scale due to shifting of $Q$ from spring to autumn (Table 3).

\section{Discussion}

\section{a. Performance advantages and limitations}

Simulations using the PITRI method substantially outperformed those using the uniform method in simulating hydrologic terms at annual and seasonal scales. At these scales, biases of the PITRI method for $Q$ were negligible, despite ignoring large variability in event timing. This implies that, in most cases, long-term mean fluxes in our simulations were not sensitive to the exact timing of events. Furthermore, both methods yielded $Q_{\text {day }}$ that had high temporal correlations (0.966 for PITRI and 0.950 for uniform) with simulations that used observed $P$, suggesting that the lack of temporal variability in event duration or timing had little impact on the variability of $Q_{\text {day }}$. To the extent that the VIC model is representative of hydrologic models in general, this implies that a deterministic approach such as PITRI can yield sufficiently accurate estimates of hourly $P$ for many large-scale hydrologic applications if it preserves mean duration and peak time; variability about these means is of secondary importance.

However, for climates in which a large portion of annual precipitation falls on days with a mix of temperatures above and below freezing, the lack of variability in timing of the PITRI method potentially can create biases in $Q$ and SWE at the seasonal scale. As shown in Figs. 10 and 11 , this problem was confined to the mountains in the NW quadrant of the CONUS_MX domain. Our results showed that, in these cases, using the uniform method yielded a smaller bias in $\mathrm{SWE}_{\max }$. A partial remedy could be to improve the accuracy of Eq. (6) to yield longer durations in this region (Fig. 4c), although, given the large scatter in observed $t_{\mathrm{pk}}$ at USCRN stations (Table 2), this would likely still concentrate too much $P$ in the warm part of the diurnal cycle due to temporal invariance of $t_{\mathrm{pk}}$. Determination of which method is best warrants further study involving comparison with field observations and consideration of other factors that influence snow accumulation, including assumed rain/snow threshold temperatures (Jennings et al. 2018). Another solution would be to implement a hybrid approach, in which uniform disaggregation is used on days for which daily minimum air temperature falls below $0^{\circ} \mathrm{C}$, and PITRI on all other days. This approach has been implemented as a "mix" option in MetSim.

At hourly scales, however, both methods performed relatively poorly in reproducing the statistics of $P$ and $Q$. Again, the temporal invariance of these deterministic methods played a role. Both methods exhibited large biases at high values of $P_{\max }$ and $Q_{\max }$, likely due to 1 ) holding event duration constant (Fig. 9b) and 2) the simple hyetograph shapes poorly approximating hourly $P$ (e.g., the lack of skewness, as shown in Fig. 9c). Improving the performance of PITRI at short time scales might require implementing a relationship between event duration and daily (in addition to monthly) 

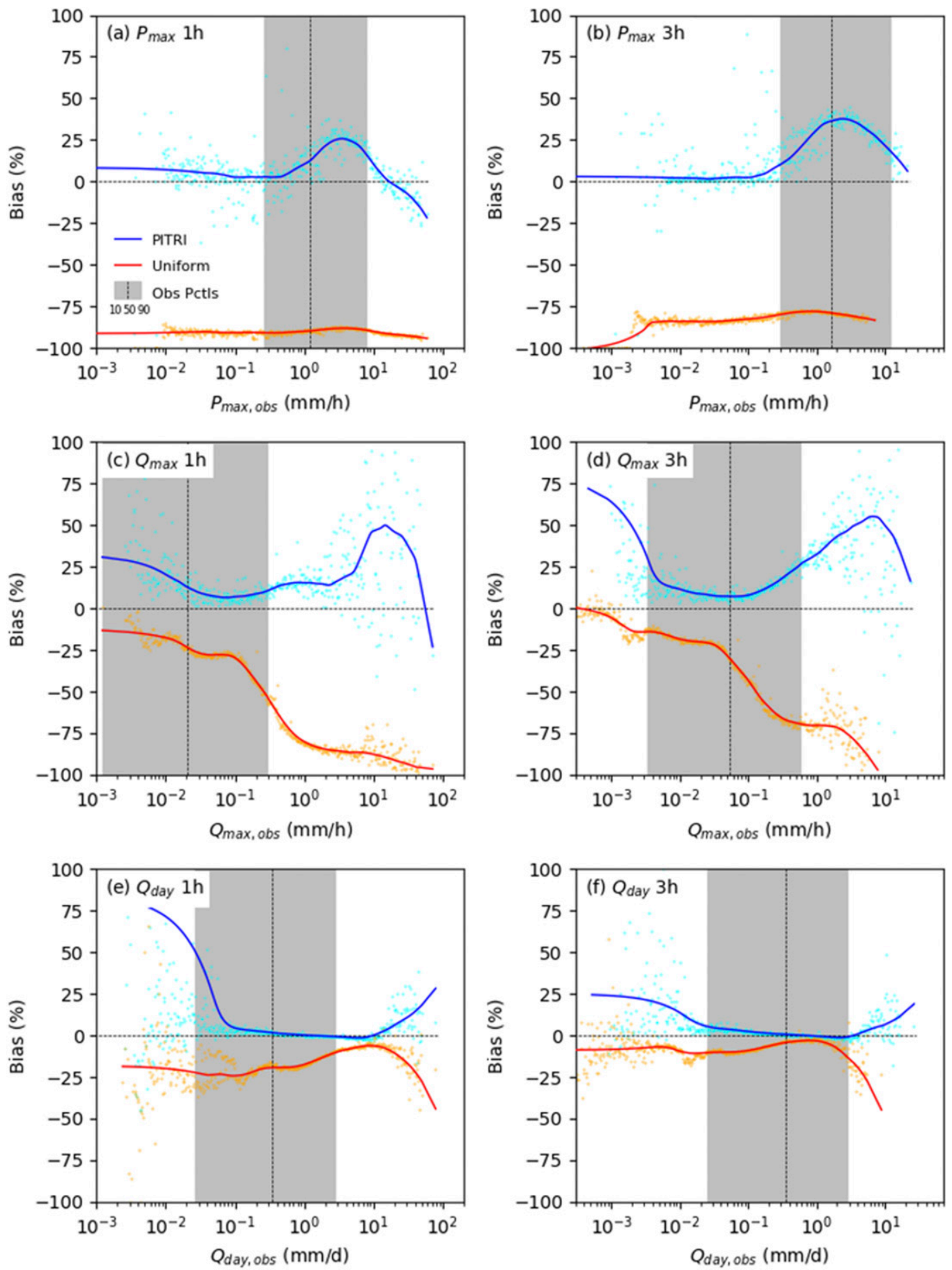

FIG. 8. Biases of VIC model simulations driven by $P$ disaggregated via the PITRI and uniform disaggregation schemes at USCRN stations $(N=128)$, relative to simulations driven by observed $P(\mathrm{obs})$. Biases are plotted for 1 -h and 3-h simulations, for (a),(b) $P_{\max }$; (c),(d) $Q_{\max }$; and (e),(f) $Q_{\text {day. }}$ Biases in each term are expressed as a percentage of the term from the observation-driven simulation. Points represent the mean value across all stations and days for which the observed variable fell in a given range. Solid lines are corresponding LOWESS curves using a $20 \%$ window drawn through the points. Shading indicates the range between the 10th and 90th percentiles of the observed variable. 

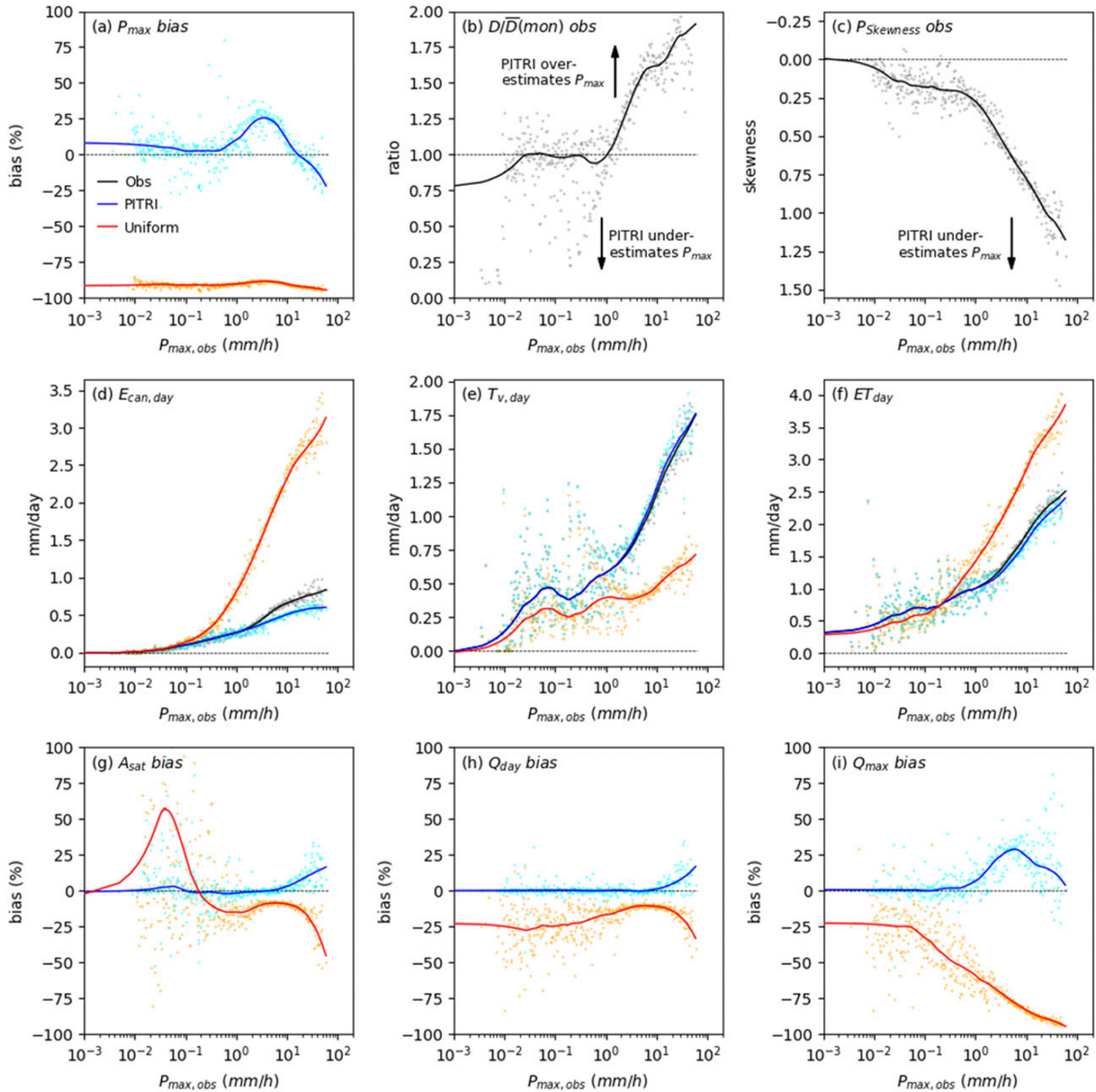

FIG. 9. Biases of PITRI and uniform methods, along with factors that influence them, as a function of $P_{\text {max,obs. }}$ (a) Biases in $P_{\text {max }}$. (b) Ratio of $D$ to $D_{\text {mon. }}$ (c) Skewness of observed hourly within-event $P$. (d)-(f) Daily canopy evaporation, transpiration, and total ET, from simulations driven by $P$ from observations (obs), PITRI, and uniform methods. (g)-(i) Biases in $A_{\text {sat }}, Q_{\text {max }}$, and $Q_{\text {day. }}$ Points represent the mean value across stations and days for which $P_{\text {max,obs }}$ falls in a given range of $\log \left(P_{\max , o b s}\right)$. Solid lines are LOWESS curves using a $20 \%$ window drawn through the points.

$P$ and/or introducing one or more shape parameters into the hyetograph. Accordingly, approaches that more accurately capture the distribution of hourly $P$ are recommended for studies of maximum hourly runoff rates.

\section{b. Implications for regional hydrologic modeling}

The biases of the uniform disaggregation approach have had a potentially large impact on regional hydrologic modeling efforts. Uniform disaggregation has been employed in numerous prior studies using the VIC model (Hamlet and Lettenmaier 1999; Nijssen et al. 2001a; Maurer et al. 2002; Christensen et al. 2004; Wood et al. 2004; Andreadis et al. 2005; Barnett et al. 2005; Hamlet et al. 2005; Mote et al. 2005; Sheffield et al. 2006; Westerling et al. 2006; Cayan et al. 2010; Vano et al. 2012; Livneh et al. 2013; L2015). In most of 

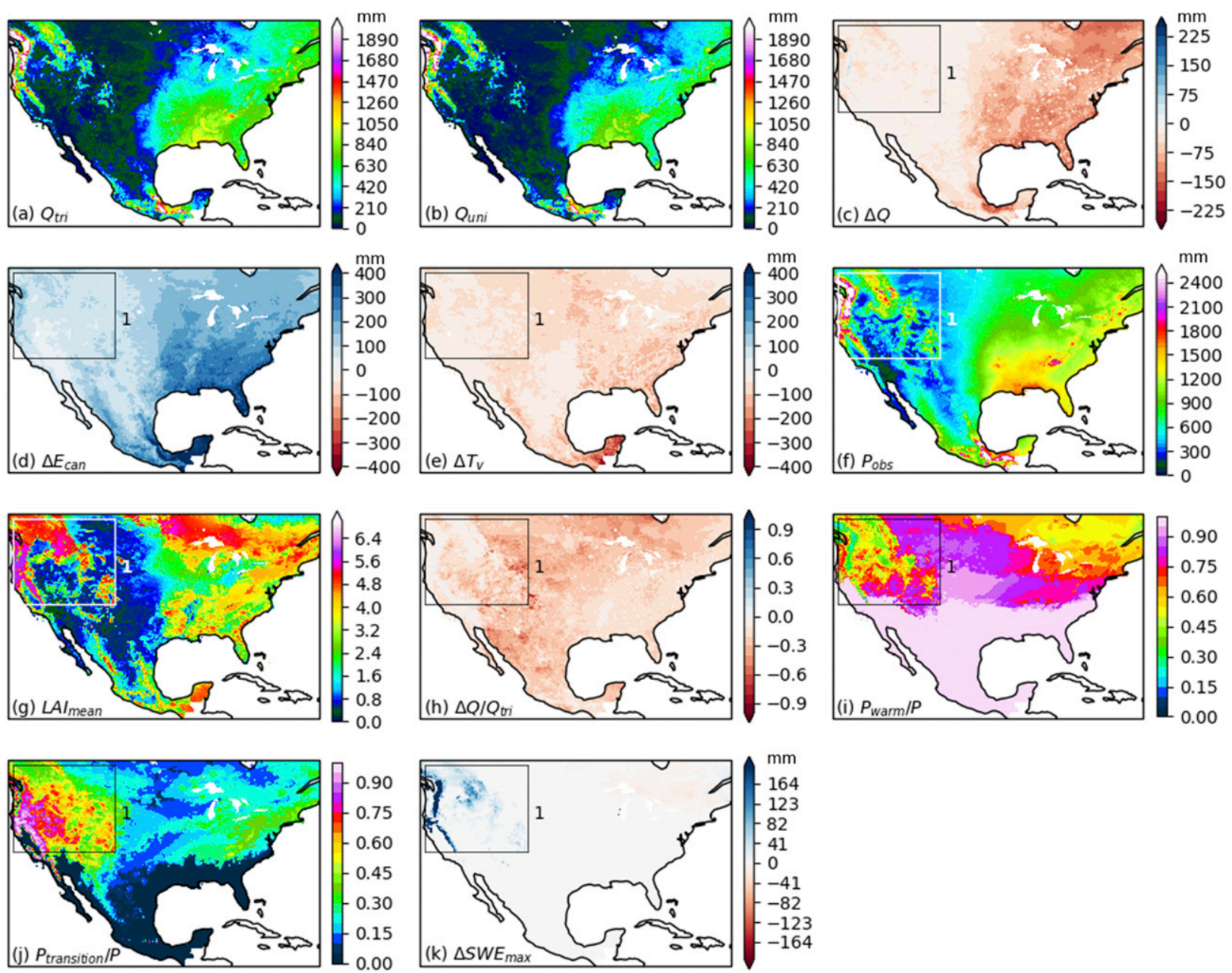

FIG. 10. Impact of $P$ disaggregation scheme on mean annual $Q$, and explanatory factors, over the CONUS_MX domain for the period 1981-2013, for VIC simulations at 1-h time step. (a),(b) The $Q$ from simulations driven by PITRI $\left(Q_{\text {tri }}\right)$ and uniform $\left(Q_{\text {uni }}\right) P$ disaggregation, respectively. (c) Difference $\Delta Q=Q_{\text {uni }}-Q_{\text {tri. }}$ (d),(e) Differences in $E_{\text {can }}$ and $T_{v}$ between uniform and PITRI schemes. (f) Annual $P$ from L2015. (g) Mean LAI over warm months (months with mean $T_{\max }>10^{\circ} \mathrm{C}$ ). (h) $\Delta Q / Q_{\text {tri. }}$ (i) Fraction of annual $P$ falling in warm months. (j) Fraction of annual $P$ falling in transition months (months with mean $T_{\min }<0$ and mean $T_{\max }>0$ ). (k) Difference in annual maximum snow water equivalent.

these studies, the VIC model soil parameters were calibrated to optimize the agreement between simulated and observed streamflow at a number of gauges within the region of interest. Due to the assumptions inherent in the uniform method, these studies may have inadvertently compensated for biases in $Q$ when calibrating the model to observations. Although these parameter values might have yielded accurate estimates of historical monthly streamflows, they might not exhibit the correct sensitivities to changes in climate or land cover that are involved in projections of future flows.

\section{c. Application to observational products}

The use of uniform disaggregation may have also impacted gridded daily meteorology products. A problem faced in these products is that stations from different networks can vary as to the beginning and ending times of their 24-h intervals, leading to ambiguity in the dates of occurrence and impacting the spatial distribution of $P$. The solution implemented in L2015 for stations whose observation intervals crossed calendar days was to apportion the reported total $P$ to each calendar day (referenced to midnight local time) in proportion to the amount of overlap between that day and the observation interval. This was implicitly an assumption of a uniform $P$ distribution. Unfortunately, this guaranteed that the daily total $P$ was consistently apportioned to two smaller events on consecutive calendar days, even if the $P$ fell on only one of the two days. As a result, the L2015 product (and others such as Maurer et al. 2002; 

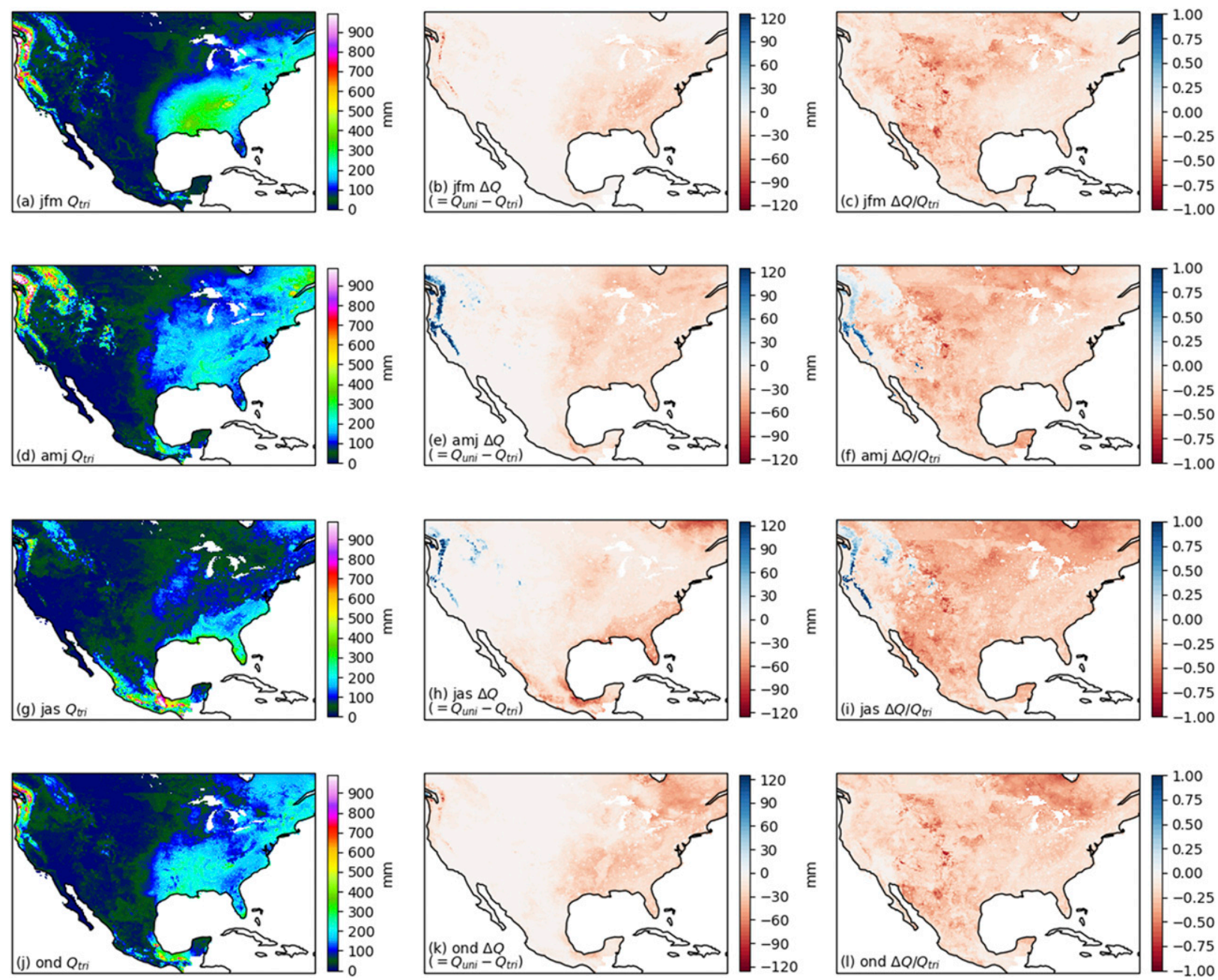

FIG. 11. Analysis of mean seasonal $Q$ from VIC simulations driven by PITRI and uniform $P$ disaggregation, 1981-2013. (left) The $Q$ from PITRI, (center) the difference $\Delta Q$ between $Q$ from uniform and PITRI, and (right) difference $\Delta Q$ normalized by $Q$ from PITRI: (a)-(c) winter, (d)-(f) spring, (g)-(i) summer, and (j)-(l) autumn.

Sheffield et al. 2006; Livneh et al. 2013) likely suffers from two types of biases: underestimation of daily total $P$ and overestimation of the number of rainy days. These biases in daily total $P$ have likely caused underestimates of daily and annual $Q$ in hydrologic simulations, in addition to any biases arising from subsequent disaggregation. A potential solution could be to use $t_{\mathrm{pk}}$ and $D$ from PITRI to estimate the timing of events within the 24-h observation intervals before apportioning $P$ to calendar days. This would likely reduce the number of cases in which a single event was split across two days, thus improving the statistics of the overall dataset.

\section{Conclusions}

The deterministic approach for disaggregating daily $P$ presented here (PITRI) captured sufficient details of the diurnal cycle to yield nearly unbiased estimates of annual $Q$ when used to drive hydrologic simulations via the VIC model. It substantially outperformed the uniform method, which yielded a mean bias of $-11 \%$ over 128 USCRN stations across the United States by overestimating canopy evaporation and underestimating throughfall to the soil surface. One limitation of the lack of daily variability in the PITRI approach is the potential for bias in snow accumulation rates in climates in which a high proportion of $P$ falls on days with a mix of temperatures above and below freezing. This problem occurred primarily in the mountains north of $39^{\circ} \mathrm{N}$ and west of $105^{\circ} \mathrm{W}$. Furthermore, both the PITRI and uniform methods yielded poor performance in reproducing statistics of $P$ and $Q$ at subdaily scales, suggesting that they are not well suited for studies of extremes. Nevertheless, the good overall performance of PITRI suggests 
that more sophisticated stochastic approaches may not be necessary for large-scale hydrologic applications focused on daily and longer time scales. PITRI also has potential application to reducing biases in gridded daily observed meteorological datasets.

Acknowledgments. The authors acknowledge National Science Foundation Grants SES-1462086 and SES1444755 and a grant from Google Earth Engine. We thank Andrew Ballinger and Kenneth Kunkel of North Carolina State University and Bart Nijssen, Andrew Bennett, Diana Gergel, and Joe Hamman of the University of Washington for their feedback on this effort. Python code implementing the PITRI algorithm is available as part of MetSim (https://github.com/UWHydro/MetSim/releases/tag/1.0.0_tri). Parameters for the CONUS_MX domain are available at Zenodo (see Bohn et al. 2018).

\section{REFERENCES}

Adam, J. C., E. A. Clark, D. P. Lettenmaier, and E. F. Wood, 2006: Correction of global precipitation products for orographic effects. J. Climate, 19, 15-38, https://doi.org/10.1175/ JCLI3604.1.

Adler, R. F., and Coauthors, 2003: The version-2 Global Precipitation Climatology Project (GPCP) monthly precipitation analysis (1979-present). J. Hydrometeor., 4, 1147-1167, https://doi.org/10.1175/1525-7541(2003)004<1147: TVGPCP $>2.0 . \mathrm{CO} ; 2$.

Alduchov, O. A., and R. E. Eskridge, 1996: Improved Magnus form approximation of saturation vapor pressure. J. Appl. Meteor., 35, 601-609, https://doi.org/10.1175/1520-0450(1996)035<0601: IMFAOS $>2.0 . \mathrm{CO} ; 2$.

Andreadis, K. M., E. A. Clark, A. W. Wood, A. F. Hamlet, and D. P. Lettenmaier, 2005: Twentieth-century drought in the conterminous United States. J. Hydrometeor., 6, 985-1001, https://doi.org/10.1175/JHM450.1.

—, P. Storck, and D. P. Lettenmaier, 2009: Modeling snow accumulation and ablation processes in forested environments. Water Resour. Res., 45, W05429, https://doi.org/ 10.1029/2008WR007042.

Arnaud, P., and J. Lavabre, 1999: Using a stochastic model for generating hourly hyetographs to study extreme rainfalls. Hydrol. Sci. J., 44, 433-446, https://doi.org/10.1080/ 02626669909492238.

— , and — 2002: Coupled rainfall model and discharge model for flood frequency estimation. Water Resour. Res., 38, 1075, https://doi.org/10.1029/2001WR000474.

Arnold, J. G., and J. R. Williams, 1989: Stochastic generation of internal storm structure at a point. Trans. ASAE, 32, 01610167, https://doi.org/10.13031/2013.30976.

Baldocchi, D., and Coauthors, 2001: FLUXNET: A new tool to study the temporal and spatial variability of ecosystem-scale carbon dioxide, water vapor, and energy flux densities. Bull. Amer. Meteor. Soc., 82, 2415-2434, https://doi.org/10.1175/ 1520-0477(2001)082<2415:FANTTS $>2.3$.CO;2.

Ball, J. E., 1994: The influence of storm temporal patterns on catchment response. J. Hydrol., 158, 285-303, https://doi.org/ 10.1016/0022-1694(94)90058-2.
Barnett, T. P., J. C. Adam, and D. P. Lettenmaier, 2005: Potential impacts of a warming climate on water availability in snow-dominated regions. Nature, 438, 303, https://doi.org/10.1038/nature04141.

Bennett, A., J. J. Hamman, B. Nijssen, E. A. Clark, and K. M. Andreadis, 2018: UW-Hydro/MetSim: Version 1.1.0. Zenodo, accessed 7 June 2018, http://doi.org/10.5281/zenodo.1256120.

Bohn, T. J., and E. R. Vivoni, 2016: Process-based characterization of evapotranspiration sources over the North American monsoon region. Water Resour. Res., 52, 358-384, https:// doi.org/10.1002/2015WR017934.

- B. Livneh, J. W. Oyler, S. W. Running, B. Nijssen, and D. P. Lettenmaier, 2013: Global evaluation of MTCLIM and related algorithms for forcing of ecological and hydrological models. Agric. For. Meteor., 176, 38-49, https:// doi.org/10.1016/j.agrformet.2013.03.003.

— , K. M. Whitney, G. Mascaro, and E. R. Vivoni, 2018: Parameters for PITRI precipitation temporal disaggregation over continental US, Mexico, and southern Canada, 19812013 (version 1). Zenodo, accessed 13 February 2019, https:// doi.org/10.5281/zenodo.1402222.

Bonnin, G. M., D. Martin, B. Lin, T. Parzybok, M. Yekta, D. Riley, D. Brewer, and L. Hiner, 2007: Updates to NOAA precipitation frequency atlases. World Environmental and Water Resources Congress 2007: Restoring Our Natural Habitat, K. C. Kabbes, Ed., ASCE, 1-10, https://doi.org/10.1061/40927(243)413.

Brooks, R. H., and A. T. Corey, 1964: Hydraulic properties of porous media and their relation to drainage design. Trans. ASAE, 7, 0026-0028, https://doi.org/10.13031/2013.40684.

Cayan, D. R., T. Das, D. W. Pierce, T. P. Barnett, M. Tyree, and A. Gershunov, 2010: Future dryness in the southwest US and the hydrology of the early 21st century drought. Proc. Natl. Acad. Sci. USA, 107, 21 271-21276, https://doi.org/10.1073/ pnas.0912391107.

Christensen, N. S., A. W. Wood, N. Voisin, D. P. Lettenmaier, and R. N. Palmer, 2004: The effects of climate change on the hydrology and water resources of the Colorado River basin. Climatic Change, 62, 337-363, https://doi.org/10.1023/ B:CLIM.0000013684.13621.1f.

Connolly, R., J. Schirmer, and P. Dunn, 1998: A daily rainfall disaggregation model. Agric. For. Meteor., 92, 105-117, https:// doi.org/10.1016/S0168-1923(98)00088-4.

Dai, A., 2001: Global precipitation and thunderstorm frequencies. Part II: Diurnal variations. J. Climate, 14, 1112-1128, https:// doi.org/10.1175/1520-0442(2001)014<1112:GPATFP>2.0.CO;2.

Deidda, R., R. Benzi, and F. Siccardi, 1999: Multifractal modeling of anomalous scaling laws in rainfall. Water Resour. Res., 35, 1853-1867, https://doi.org/10.1029/1999WR900036.

Diamond, H. J., and Coauthors, 2013: U.S. Climate Reference Network after one decade of operations: Status and assessment. Bull. Amer. Meteor. Soc., 94, 485-498, https://doi.org/ 10.1175/BAMS-D-12-00170.1.

Domínguez-Mora, R., M. Arganis-Juárez, A. Mendoza-Reséndiz, E. Carrizosa-Elizondo, H. Guzmán-García, B. Echavarría-Soto, and J. Baños-Martínez, 2014: Time and spatial synthetic hourly rainfall generation in the Basin of Mexico. Int. J. River Basin Manage., 12, 367-375, https://doi.org/10.1080/15715124.2013.842574.

El-Jabi, N., and S. Sarraf, 1991: Effect of maximum rainfall position on rainfall-runoff relationship. J. Hydraul. Eng., 117, 681-685, https://doi.org/10.1061/(ASCE)0733-9429(1991)117:5(681).

FAO/UNESCO, 1998: Digital soil map of the world and derived soil properties. Accessed 1 January 2018, http://www.fao.org/ soils-portal/soil-survey/soil-maps-and-databases/faounescosoil-map-of-the-world/en/. 
Fatichi, S., and Coauthors, 2016: An overview of current applications, challenges, and future trends in distributed processbased models in hydrology. J. Hydrol., 537, 45-60, https:// doi.org/10.1016/j.jhydrol.2016.03.026.

Franchini, M., and M. Pacciani, 1991: Comparative analysis of several conceptual rainfall-runoff models. J. Hydrol., 122, 161-219, https://doi.org/10.1016/0022-1694(91)90178-K.

Grassotti, C., R. N. Hoffman, E. R. Vivoni, and D. Entekhabi, 2003: Multiple-timescale intercomparison of two radar products and rain gauge observations over the Arkansas-Red River basin. Wea. Forecasting, 18, 1207-1229, https://doi.org/ 10.1175/1520-0434(2003)018<1207:MIOTRP > 2.0.CO;2.

Grimaldi, S., and F. Serinaldi, 2006: Design hyetograph analysis with 3-copula function. Hydrol. Sci. J., 51, 223-238, https:// doi.org/10.1623/hysj.51.2.223.

Guzzetti, F., S. Peruccacci, M. Rossi, and C. P. Stark, 2008: The rainfall intensity-duration control of shallow landslides and debris flows: An update. Landslides, 5, 3-17, https://doi.org/ 10.1007/s10346-007-0112-1.

Hamlet, A. F., and D. P. Lettenmaier, 1999: Effects of climate change on hydrology and water resources in the Columbia River Basin. J. Amer. Water Resour. Assoc., 35, 1597-1623, https://doi.org/10.1111/j.1752-1688.1999.tb04240.x.

— P. W. Mote, M. P. Clark, and D. P. Lettenmaier, 2005: Effects of temperature and precipitation variability on snowpack trends in the western United States. J. Climate, 18, 4545-4561, https://doi.org/10.1175/JCLI3538.1.

Hamman, J. J., B. Nijssen, T. J. Bohn, D. R. Gergel, and Y. Mao, 2018: The Variable Infiltration Capacity Model, version 5 (VIC-5): Infrastructure improvements for new applications and reproducibility. Geosci. Model Dev., 11, 3481-3496, https://doi.org/10.5194/gmd-11-3481-2018.

Hansen, M., R. DeFries, J. R. Townshend, and R. Sohlberg, 2000: Global land cover classification at $1 \mathrm{~km}$ spatial resolution using a classification tree approach. Int. J. Remote Sens., 21, 1331-1364, https://doi.org/10.1080/014311600210209.

Huff, F. A., 1967: Time distribution of rainfall in heavy storms. Water Resour. Res., 3, 1007-1019, https://doi.org/10.1029/ WR003i004p01007.

Jennings, K. S., T. S. Winchell, B. Livneh, and N. P. Molotch, 2018: Spatial variation of the rain-snow temperature threshold across the Northern Hemisphere. Nat. Commun., 9, 1148, https://doi.org/10.1038/s41467-018-03629-7.

Joyce, R. J., J. E. Janowiak, P. A. Arkin, and P. Xie, 2004: CMORPH: A method that produces global precipitation estimates from passive microwave and infrared data at high spatial and temporal resolution. J. Hydrometeor., 5, 487-503, https://doi.org/10.1175/ 1525-7541(2004)005<0487:CAMTPG > 2.0.CO;2.

Katz, R. W., and M. B. Parlange, 1995: Generalizations of chaindependent processes: Application to hourly precipitation. Water Resour. Res., 31, 1331-1341, https://doi.org/10.1029/94WR03152.

Klazura, G. E., and D. A. Imy, 1993: A description of the initial set of analysis products available from the NEXRAD WSR-88D system. Bull. Amer. Meteor. Soc., 74, 1293-1312, https://doi.org/ 10.1175/1520-0477(1993)074<1293:ADOTIS > 2.0.CO;2.

Lambourne, J., and D. Stephenson, 1987: Model study of the effect of temporal storm distributions on peak discharges and volumes. Hydrol. Sci. J., 32, 215-226, https://doi.org/10.1080/ 02626668709491179.

Liang, X., D. P. Lettenmaier, E. F. Wood, and S. J. Burges, 1994: A simple hydrologically based model of land surface water and energy fluxes for general circulation models. J. Geophys. Res., 99, 14 415-14 428, https://doi.org/10.1029/94JD00483.
Livneh, B., E. A. Rosenberg, C. Lin, B. Nijssen, V. Mishra, K. M. Andreadis, E. P. Maurer, and D. P. Lettenmaier, 2013: A longterm hydrologically based dataset of land surface fluxes and states for the conterminous United States: Update and extensions. J. Climate, 26, 9384-9392, https://doi.org/10.1175/ JCLI-D-12-00508.1.

—, T. J. Bohn, D. W. Pierce, F. Munoz-Arriola, B. Nijssen, R. Vose, D. R. Cayan, and L. Brekke, 2015: A spatially comprehensive, hydrometeorological data set for Mexico, the U.S., and southern Canada 1950-2013. Nat. Sci. Data, 2, 150042, https://doi.org/10.1038/sdata.2015.42.

Maraun, D., and Coauthors, 2010: Precipitation downscaling under climate change: Recent developments to bridge the gap between dynamical models and the end user. Rev. Geophys., $\mathbf{4 8}$, RG3003, https://doi.org/10.1029/2009RG000314.

Marks, D., A. Winstral, M. Reba, J. Pomeroy, and M. Kumar, 2013: An evaluation of methods for determining during-storm precipitation phase and the rain/snow transition elevation at the surface in a mountain basin. Adv. Water Resour., 55, 98-110, https://doi.org/10.1016/j.advwatres.2012.11.012.

Mascaro, G., 2017: Multiscale spatial and temporal statistical properties of rainfall in central Arizona. J. Hydrometeor., 18 , 227-245, https://doi.org/10.1175/JHM-D-16-0167.1.

—_, E. R. Vivoni, D. J. Gochis, C. J. Watts, and J. C. Rodriguez, 2014: Temporal downscaling and statistical analysis of rainfall across a topographic transect in northwest Mexico. J. Appl. Meteor. Climatol., 53, 910-927, https://doi.org/ 10.1175/JAMC-D-13-0330.1.

Maurer, E., A. Wood, J. Adam, D. Lettenmaier, and B. Nijssen, 2002: A long-term hydrologically based dataset of land surface fluxes and states for the conterminous United States. J. Climate, 15, 3237-3251, https://doi.org/10.1175/ 1520-0442(2002)015<3237:ALTHBD>2.0.CO;2.

Monteith, J. L., 1965: Evaporation and environment. Symp. Soc. Exp. Biol., 19, 205-234.

Mote, P. W., A. F. Hamlet, M. P. Clark, and D. P. Lettenmaier, 2005: Declining mountain snowpack in western North America. Bull. Amer. Meteor. Soc., 86, 39-50, https://doi.org/10.1175/ BAMS-86-1-39.

Müller, H., and U. Haberlandt, 2015: Temporal rainfall disaggregation with a cascade model: From single-station disaggregation to spatial rainfall. J. Hydrol. Eng., 20, 04015026, https:// doi.org/10.1061/(ASCE)HE.1943-5584.0001195.

Myneni, R. B., R. Ramakrishna, R. Nemani, and S. W. Running, 1997: Estimation of global leaf area index and absorbed PAR using radiative transfer models. IEEE Trans. Geosci. Remote Sens., 35, 1380-1393, https://doi.org/10.1109/36.649788.

Nijssen, B., G. M. O'donnell, A. F. Hamlet, and D. P. Lettenmaier, 2001a: Hydrologic sensitivity of global rivers to climate change. Climatic Change, 50, 143-175, https://doi.org/10.1023/ A:1010616428763.

_ R. Rchnur, and D. P. Lettenmaier, 2001b: Global retrospective estimation of soil moisture using the variable infiltration capacity land surface model, 1980-93. J. Climate, 14, 1790-1808, https:// doi.org/10.1175/1520-0442(2001)014<1790:GREOSM>2.0.CO;2.

Olsson, J., 1998: Evaluation of a scaling cascade model for temporal rain-fall disaggregation. Hydrol. Earth Syst. Sci., 2, 1930, https://doi.org/10.5194/hess-2-19-1998.

Paniconi, C., and M. Putti, 2015: Physically based modeling in catchment hydrology at 50: Survey and outlook. Water Resour. Res., 51, 7090-7129, https://doi.org/10.1002/2015WR017780.

Perica, S., and E. Foufoula-Georgiou, 1996: Model for multiscale disaggregation of spatial rainfall based on coupling meteorological 
and scaling descriptions. J. Geophys. Res., 101, $26347-$ 26 361, https://doi.org/10.1029/96JD01870.

Prein, A. F., R. M. Rasmussen, K. Ikeda, C. Liu, M. P. Clark, and G. J. Holland, 2017: The future intensification of hourly precipitation extremes. Nat. Climate Change, 7, 48, https://doi.org/ 10.1038/nclimate3168.

Rodriguez-Iturbe, I., V. K. Gupta, and E. Waymire, 1984: Scale considerations in the modeling of temporal rainfall. Water Resour. Res., 20, 1611-1619, https://doi.org/ 10.1029/WR020i011p01611.

Schreiner-McGraw, A. P., and E. R. Vivoni, 2018: On the sensitivity of hillslope runoff and channel transmission losses in arid piedmont slopes. Water Resour. Res., 54, 4498-4518. https:// doi.org/10.1029/2018WR022842.

Sheffield, J., G. Goteti, and E. F. Wood, 2006: Development of a 50 -year high-resolution global dataset of meteorological forcings for land surface modeling. J. Climate, 19, 3088-3111, https://doi.org/10.1175/JCLI3790.1.

Simpson, J., R. F. Adler, and G. R. North, 1988: A proposed Tropical Rainfall Measuring Mission (TRMM) satellite. Bull. Amer. Meteor. Soc., 69, 278-295, https://doi.org/10.1175/ 1520-0477(1988)069<0278:APTRMM>2.0.CO;2.

Sorooshian, S., K.-L. Hsu, X. Gao, H. V. Gupta, B. Imam, and D. Braithwaite, 2000: Evaluation of PERSIANN system satellite-based estimates of tropical rainfall. Bull. Amer. Meteor. Soc., 81, 2035-2046, https://doi.org/10.1175/15200477(2000)081<2035:EOPSSE > 2.3.CO;2.

Stephenson, D., 1984: Kinematic study of effects of storm dynamics on runoff hydrographs. Water SA, 10, 189-196.

Todini, E., 1988: Rainfall-runoff modeling-Past, present and future. J. Hydrol., 100, 341-352, https://doi.org/10.1016/ 0022-1694(88)90191-6.
Vano, J. A., T. Das, and D. P. Lettenmaier, 2012: Hydrologic sensitivities of Colorado River runoff to changes in precipitation and temperature. J. Hydrometeor., 13, 932949, https://doi.org/10.1175/JHM-D-11-069.1.

Venugopal, V., E. Foufoula-Georgiou, and V. Sapozhnikov, 1999: A space-time downscaling model for rainfall. J. Geophys. Res., 104, 19 705-19721, https://doi.org/10.1029/1999JD900338.

Westerling, A. L., H. G. Hidalgo, D. R. Cayan, and T. W. Swetnam, 2006: Warming and earlier spring increase western U.S. forest wildfire activity. Science, 313, 940-943, https://doi.org/10.1126/ science.1128834.

Wigmosta, M. S., L. W. Vail, and D. P. Lettenmaier, 1994: A distributed hydrology-vegetation model for complex terrain. Water Resour. Res., 30, 1665-1679, https://doi.org/ 10.1029/94WR00436.

Wood, A. W., L. R. Leung, V. Sridhar, and D. Lettenmaier, 2004: Hydrologic implications of dynamical and statistical approaches to downscaling climate model outputs. Climatic Change, 62, 189-216, https://doi.org/10.1023/B:CLIM.0000013685.99609.9e.

Wüest, M., C. Frei, A. Altenhoff, M. Hagen, M. Litschi, and C. Schär, 2010: A gridded hourly precipitation dataset for Switzerland using rain-gauge analysis and radar-based disaggregation. Int. J. Climatol., 30, 1764-1775, https://doi.org/ $10.1002 /$ joc. 2025 .

Xia, Y., and Coauthors, 2012: Continental-scale water and energy flux analysis and validation for the North American Land Data Assimilation System project phase 2 (NLDAS-2): 1. Intercomparison and application of model products. J. Geophys. Res., 117, D03109, https://doi.org/10.1029/2011JD016048.

Zhu, C., and D. P. Lettenmaier, 2007: Long-term climate and derived surface hydrology and energy flux data for Mexico: 1925-2004. J. Climate, 20, 1936-1946, https://doi.org/10.1175/JCLI4086.1. 